\title{
Beiträge zur Kenntnis der Histologie und Funktion des Hymenopterendarmes.
}

\section{Inaugural-Dissertation}

zur Erlangung der Doktorwürde der hohen philosophischen Fakultät der Universität Leipzig

vorgelegt von

Kurt Loele

Jena

Gustav Fischer

1913. 
Angenommen von der III. Sektion auf Grund der Gutachten der Herren Chun und Pfeffer.

Leipzig, den 17. Juli 1913.

Der Procancellar.

Le Blanc.

Veröffentlicht in der "Zeitschrift für allgem. Physiologie", Bd. XVI, Heft 1, s. $1-36$. 


\section{REMOTE STORAGE}

Meinen Eltern 


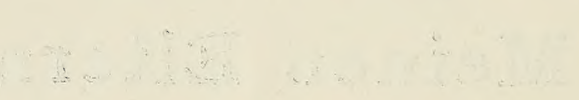




\section{In halt.}

Seite

Einleitung . . . . . . . . . . . . . . . . . . . 2

Histologie des Mitteldarmes . . . . . . . . . . . . . 4

Der Enddarm . . . . . . . . . . . . . . . . . . . 11

Die Sekretionserscheinungen des Mitteldarmes . . . . . . . . 14

Versuche zur Fettresorption . . . . . . . . . . . . . 25

Literatur . . . . . . . . . . . . . . . . . . 34 


\section{Einleitung.}

Die Fülle der Insektenformen, die Mannigfaltigkeit ihrer Lebensbedingungen, die verschiedenartige Ausbildung der einzelnen Abschnitte ihres Darmkanals lassen es begreiflich erscheinen, daB selbst die Frage, welchem Darmabschnitt der Hauptanteil der Resorption zukomme, verschieden beantwortet wird. Die Resorptionsfähigkeit des Mitteldarms ist wohl für die meisten der untersuchten Arten bewiesen, dagegen gehen die Meinungen, ob auch der Enddarm dazu imstande sei, auseinander. Plateau hatte in seiner grundlegenden Arbeit über die Verdauungserscheinungen bei den Insekten außer dem Mitteldarm dem vorderen Teile des Enddarms Resorptionsvermögen zugesprochen. Biedermans hält Resorption im Enddarm vorläufig noch für zweifelhaft. BERLESE spricht den Enddarm als den hauptsächlichen Sitz der Resorption an. PetrunkewITSCH hatte auf Grund seiner Befunde an Blattiden annehmen zu können geglaubt, der Kropf der Insekten sei das Hauptorgan der Resorption. Sinety und vor allem SchuÜter wiesen nach, daß zumindest eine Resorption von Fett im Kropf nicht stattfindet.

Im Anschluß an die Arbeit SchlÜter's lag es mir ob, den Resorptionsvorgang im Darm der ausgebildeten Hymenopteren zu untersuchen, und zwar beschränkte ich mich auf die Untersuchung der Fettverdauung. Gleichzeitig sollte die Fähigkeit der Tiere, Fett aus fettfreier Kost aufzubauen, geprüft werden. Es mag im voraus erwähnt sein, daß bei den starken Freiheits- oder Nestinstinkten der Hymenopteren Fütterungsversuche große Schwierigkeiten haben, weshalb häufig nur frisch gefangenes Material untersucht werden konnte. Aber ganz abgesehen von diesen Mißständen war es fast selbstverständlich, daß es bei dieser engeren Fassung: des Themas sein Bewenden nicht haben konnte. Man wird kaum über die Resorptionsfähigkeit des Insektendarmes arbeiten können, ohne gleichzeitig auf die Sekretion und die mit ihr zusammenhängenden Erscheinungen einzugehen. Die wechselvolle Anordnung des Mitteldarmepithels der einzelnen Formen gab, soweit es die von mir angefertigten Schnitte zuließen, Anlaß zu einer vergleichend histologischen Betrachtung; desgleichen erschien eine kurze Behandlung der Histologie des Enddarmes nötig. 
Beiträge zur Kenntnis d. Histologie u. Funktion d. Hymenopterendarmes.

Nach Abschluß meiner Untersuchungen erschien eine Arbeit von STeudel über Absorption und Sekretion im Darmkanal von Insekten, hauptsächlich von Periplaneta. Sie veranlaßte mich, einige der Versuche Steudel's zu wiederholen. Steudel gibt eine ziemlich ausführliche Übersicht der einschlägigen Literatur und erlaubt mir, mich in dieser Hinsicht kurz zu fassen. Seine Arbeit soll bei Betrachtung des Sekretionsvorganges etwas eingehender besprochen werden.

Das Material wurde in der Umgebung von Leipzig und Rudolstadt in Thüringen gesammelt. Die Bestimmung der Arten resp. der Gattungen, geschah nach Sснмiеdeкnecht: Die Hymenopteren Mitteleuropas. Zur Untersuchung kamen Vertreter der Familien der Apiden, Formiciden, Vespiden, Sphegiden, Chrysididen, Pompiliden, Ichneumoniden und Tenthrediniden. Abgetötet wurde teils mit heißem Wasser, teils wurden die Tiere im Cyankaliglas betäubt, worauf nach Wegnahme des Kopfes die möglichst rasche Auspräparation d€s Darmkanals erfolgte.

Handelte es sich um den Nachweis von Fett, so geschah die Fixierung mit starker Flemming'scher Lösung, die im allgemeinen leidliche Bilder lieferte. Zu histologischen Untersuchungen erwies sich die von Frenzes und Sемichon empfohlene Sublimat-AlkoholSalpetersäure am vorteilhaftesten, da sie bessere Resultate als die zuerst angewendete Formol- oder Sublimat-Alkohol-Essigsäure ergab.

Die meist $5 \mu$ starken Schnitte wurden, soweit osmiertes Material vorlag, mit Hämalaun oder Hämatoxylin Delafield gefärbt, im übrigen neben den angegebenen Farben hauptsächlich mit Hämatoxylin Heidenhain.

Andere versuchte Fixierungs- und Färbungsmethoden zeigten keine besonderen Vorteile.

Ganz besonders drängt es mich, Herrn Privatdozent Dr. Sтеснe, der mich zu der vorliegenden Untersuchung anregte und mir mit seinen wertvollen Ratschlägen eifrig zur Seile stand, bestens zu danken; desgleichen Herrn Prof. Dr. Woltereck und Herrn Privatdozent Dr. Hempelmann. 


\section{Histologie des Mitteldarmes.}

Der Darmkanal der Hymenopteren, wie überhaupt der Insekten, gliedert sich in 3 Abschnitte, den Vorder-, Mittel- und Enddarm.

Da seine äußere Gestalt, besonders von Dufour und Bordas, eingehend beschrieben worden ist, wende ich mich sofort zur Betrachtung des histologischen Aufbaues des Mitteldarmes. Er zeigt, wie bei den übrigen Insekten, von innen nach außen folgende 3 Schichten: 1. Das Epithel mit den Regenerationskrypten, 2. Die Basalmembran oder Stützlamelle, 3. Die Muscularis, ein Netz innerer Ring- und äußerer Längsmuskelfasern. Die Untersuchung gilt vor allem dem Epithel, und wenn naturgemäß der Gegenstand auch durchaus nicht erschöpfend behandelt, und die Abhängigkeit der Epithelstruktur von dem nach der Lebensdauer größeren oder geringeren Freßbedürfnis der Tiere von vornherein erwartet werden konnte, glaubte ich doch die gemachten Befunde mitteilen zu sollen, da der Versuch einer vergleichenden Übersicht bis jetzt nicht vorlag.

Einige allgemeine Bemerkungen mögen vorausgeschickt werden. Die Epithelstruktur des Mitteldarmes der Insekten ist in erster Linie abhängig von der Anordnung und Ausbildung der Regenerationskrypten. Die Anordnung der Krypten kann meist schon aus der Beschaffenheit der äuBeren Oberfläche des Mitteldarmes erschlossen werden. Bei äußerlich glattem Mitteldarm liegen sie unregelmäßig zwischen den Epithelzellen zerstreut, bei geringeltem Mitteldarm mehr oder minder regelmäßig im Grunde der Ringwülste; ist der Mitteldarm zottig, so sind es eben die blindsackförmigen Ausstülpungen, deren blindes Ende die Krypte bildet. Diese letzte besonders für Raubkäfer charakteristische Ausbildungsweise fehlt bei den Hymenopteren vollkommen.

Frenzer hatte die Krypten für Drüsen gehalten und demgemäß von zwei grundsätzlich verschiedeneu Zellformen gesprochen. ScHiEMENz unterschied (bei der Honigbiene) keulenförmige Rand- und kugelförmige Basiszellen und glanbte den Randzellen resorptive, den Basiszellen sekretorische Funktion zuschreiben zu dürfen. Doch fand er einen allmählichen Übergang durch die zwischen Randund Basiszellen liegenden Zellen vermittelt. Seither ist von Bordas, Bugnion, Semichon u. a. bewiesen worden, daß alle Zellen von den Kryptenzellen abstammen, und somit von einem prinzipiellen Unterschied keine Rede sein kann.

Alle bis zum Darmlumen reichenden Zellen lassen bei geeigneter Fixierung einen deutlichen Stäbchensaum erkennen. Der verschiedene 
Beiträge zur Kenntnis d. Histologie u. Funktion d. Hymenopterendarmes.

Erhaltungszustand dieses Saumes veranlaßte Semichon zu der Bemerkung: „Il semblerait donc que la brosse soit une formation variable, transitoire ou même factice"; es ist aber nicht daran zu zweifeln, daß er einen integrierenden Bestandteil des Mitteldarmepithels der Hymenopteren und wohl aller Insekten bildet. Die Basalmembran ist bei den Hymenopteren stets dünn und kann hänfig nur dann nachgewiesen werden, wenn sich das Epithel etwas von ihr abgehoben hat. Mitosen, wie sie sich in den Krypten von Blatta, Hydrophilus u. a. finden, konnte ich trotz der großen Anzahl der mir vorliegenden Schnitte nirgends nachweisen. Die Muskulatur ist im allgemeinen schwach. Eine äußere Lage von Bindegewebe fehlt fast vollkommen, nur in der Gegend der Einmündung der Malpighi'schen Gefäße konnten hier und da Spuren davon beobachtet werden.

In der Reihenfolge der einzelnen Familien halte ich mich an die von Schmiedeknecht gegebene, stelle aber die Formiciden ihres etwas abweichenden Verhaltens halber an den Schluß der Betrachtung.

\section{Apidae.}

Apis mellifica (Tafelfigur 1 u. 2). Naturgemäß ist die Honigbiene oft genug untersucht worden, aber alle Autoren sind sich über die Schwierigkeit, wirklich einwandfreie Schnittbilder vom Mitteldarmepithel zu erhalten, einig. Bei schwacher Vergrößerung des frisch aufgeschnittenen Mitteldarmes fällt seine von den Ringwülsten ziemlich unabhängige polygonale Felderung auf, die sich daraus erklärt, $\mathrm{da}$ ß nur die Randzellen, also die ältesten, von den Krypten entferntesten Zellen, mit den später zu besprechenden Sekretkugeln erfüllt sind und dadurch dunkler erscheinen. Diese Randzellen und die Krypten zeigen sich auf Schnitten noch am ehesten unversehrt; dagegen sind die dazwischenliegenden Zellen fast ausnahmslos zerflossen oder sonstwie deformiert. Man wird bedenken müssen, daß es sich dabei um heranwachsende, sicher sehr turgeszente Zellen handelt, doch verlohnte die auch bei den übrigen Hymenopteren unangenehm in Erscheinung tretende schwierige Fixierbarkeit des Mitteldarmepithels vielleicht einer besonderen Untersuchung.

Bombus (lapidarius, agrorum, terrestris, variabilis). (Textfigur 1). Schon bei makroskopischer Betrachtung fällt auf, daß sich der Mitteldarm einige Millimeter hinter seinem Anfang plötzlich deutlich erweitert. Der vordere, dünnere Abschnitt reicht ungefähr so weit wie die Duplikatur des Ventiltrichters und ist von 


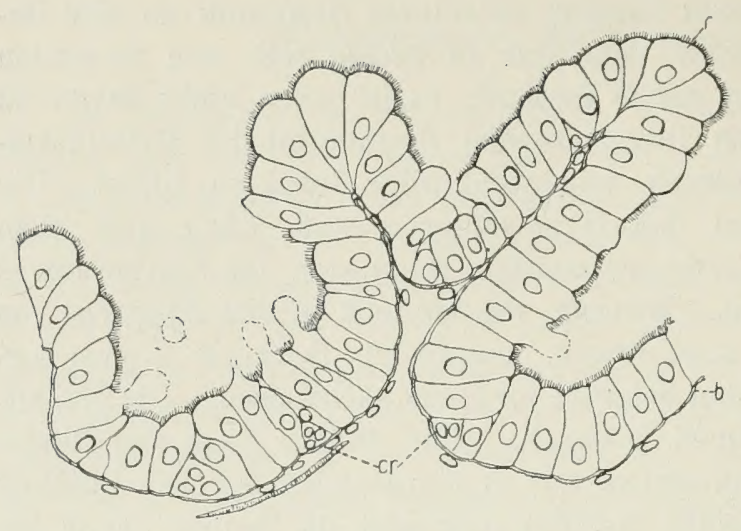

Textfig. 1. Bombus terrestris. Mitteldarmepithel.

ungemein regelmäBiger Struktur. Die streng ringförmig angeordneten Krypten liegen genau im Grunde der tiefen Falten. In dem hinteren, dickeren $\mathrm{Ab}$ schnitt des Mitteldarmes ist die Ringelung und auch die Anordnung der Krypten unregelmäBiger. Auffallend ist ferner die verschiedenartige Ausbildung des Epithels bei Weibchen und Arbeitern. Während es bei den Weibchen eine außerordentlich reiche Faltelung aufweist, die reichste, die ïberhaupt bei den untersuchten Hymenopteren zur Beobachtung kam, zeigen besonders die ersten, Ende Mai geschlupften, sehr kleinen Arbeiter ungleich einfachere Verhältnisse, da bei ihnen die viel weiter auseinanderstehenden Wülste sich abflachen und nur wenig ins Lumen des Darmes hineinragen. Später im Jahr wird die Epithelstruktur des Arbeiterdarmes komplizierter, erreicht aber nicht völlig die der Weibchen. Die Hummelmännchen verhalten sich ungefähr wie die zuerst geschlüpften Arbeiter. Ein untersuchtes Weibchen von Psithyrus rupestris unterschied sich nicht wesentlich von den BombusWeibchen.

Das Epithel der Anthophoren (A. acervorum) läßt keinen Unterschied zwischen den Weibchen und den zeitig im Frühjahr fliegenden Männchen erkennen. Die Ringwülste sind flach, die Krypten unregelmäßig verteilt.

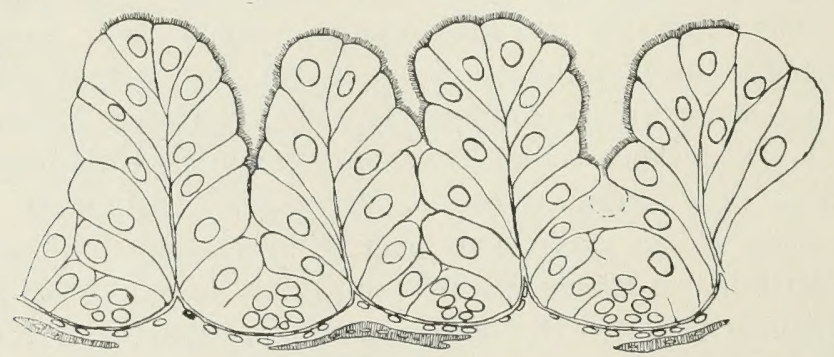

Textfig. 2. Halictus rubicundus. Längsschnitt. 
Bei den Andrenen (A. carbonaria, fulva, Hessae) entspricht der starken Ringelung des Mitteldarmes die regelmäßige Struktur des Epithels. Die Krypten sind ringförmig angeordnet. Der Höhepunkt von Regelmäßigkeit wird aber erst bei Halictus (H. rubicundus) erreicht. Hier wechseln ganz gleichmäßig durch den gesamten Mitteldarm die Kryptenringe mit den Randzellenwülsten, und es resultieren hieraus die reizvollen Bilder, von denen Textfigur 2 eine Vorstellung zu geben versucht.

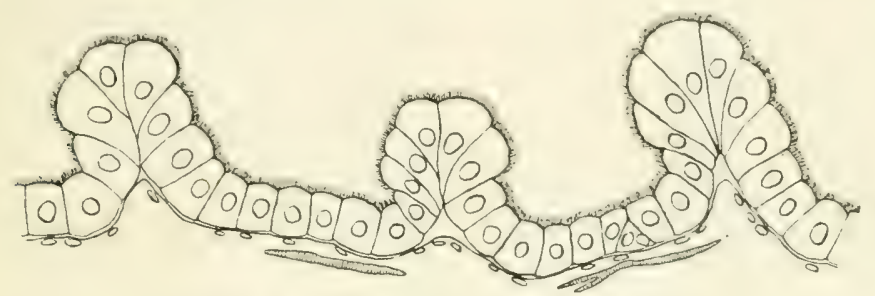

Textfig. 3. Osmia bicornis. Längsschnitt.

Die Randzellenwülste von Osmia (O. bicornis), (Textfigur 3) stehen ziemlich weit auseinander, die Krypten sind ringförmig angeordnet, fallen aber wegen ihrer Kleimheit wenig in die Augen. Nan findet in ihnen kaum mehr als 2-3 Kerne. Ganz ähnlich ist das Epithel von Melecta armata (Textfigur 4), nur reichen hier die Randzellenwülste etwas weiter ins Darmlumen vor. Am primitivsten von allen untersuchten Apiden rerhalten sich die Schmarotzerbienen der Gattung Nomada. Untersucht wurde $\mathrm{N}$. succincta, deren Mitteldarmepithel infolge

Verstreichens der Ringfalten fast glatt erscheint. Die Krypten sind noch seltener und unauffailliger als bei Osmia und Melecta.

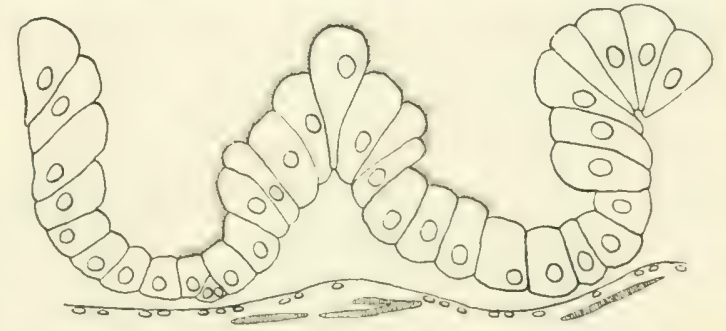

Textfig. 4. Melecta armata. Lüngsschnitt.

\section{Vespidae.}

Während die Gattung Odynerus (Hoplomerus spinipes) noch wohlausgebildete, wenn auch nicht eben häufige hrypten besit\%t, kommt es bei Vespa (crabro. media, saxonica, germanica, vulgaris) zu ciner bedeutenden Vereinfachung der Epithehtruktur. Nu im 


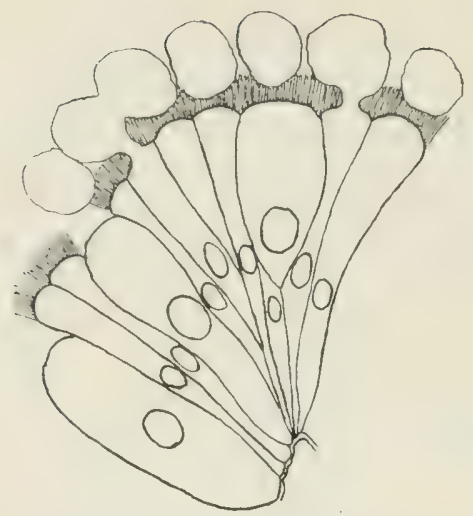

Textfig. 5. Vespa germanica. Längsschnitt. Die Blasen über den Zellen sind Kunstprodukte. hintersten Abschnitt des Mitteldarmes finden sich Krypten, im weitaus überwiegenden vorderen Teile sind sie zu einzelnen Regenerationszellen reduziert. Die Zellerneuerung ist demgemäß eine jedenfalls recht beschränkte; Abstoßung ganzer Zellen, oder wenigstens ron Kernen, wie sie bei Apis, Bombus u. a. häufig ist, konnte niemals beobachtet werden (Textfigur 5).

Sphegidae.

Crabro (Lindenius albilabris), Mellinus arvensis, Ammophila rabulosa (Textfigur 6). Die 3 untersuchten Arten wiesen im wesentlichen gleiche Epithelstruktur auf, die sich eng an die der Apiden, speziell Halictus, anschließt. Die Krypten sind ringförmig angeordnet, die Randzellenwülste reichen wenig weit ins Darmlumen vor. Auffällig ist die verhältnismäßige Größe der Kerne. Leider war es mir nicht möglich, die neben den eigentlichen Krypten gelegenen Zellen einwandfrei zu fixieren, sie erschienen auf allen Schnittbildern gequollen und ungefärbt.

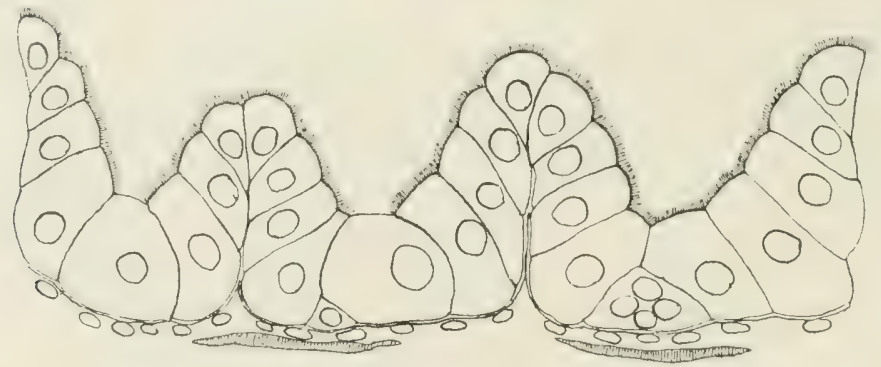

Textfig. 6. Ammophila sabulosa. Längsschnitt.

\section{Chrysididae.}

Untersucht wurde nur Chrysis ignita (Textfigur 7). Das Epithel ist von seln einfachem, fast glattem Ban. Die Krypten sind selten und klein. 
Beiträge zur Kenntnis d. Histologie u. Funktion d. Hymenopterendarmes.

Pompilidae.

Pompilus viaticus. Priocnemis fuscus ('Tafelfigur 3). Das Epithel ist wenig gewulstet, sonst aber wohlentwickelt. Die Randzellen sind langgestreckt, die Krypten ungeführ ringförmig angeordnet.

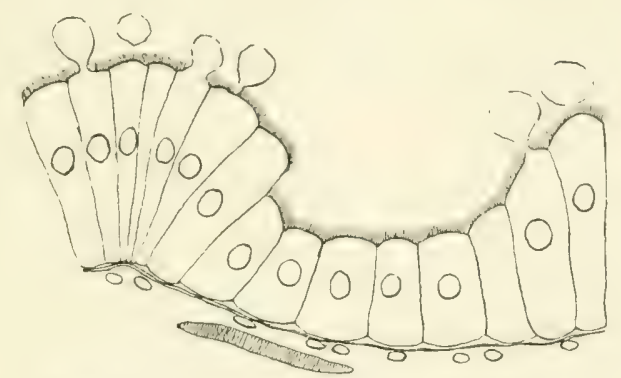

'lextfig. 7. Chrysis ignita. Längsschnitt.

I chneumonidae.

Zur Untersuchung kamen einige größere Arten der Gattung Ichneumon. Das Epithel ist in der vorderen Hälfte des Mitteldarmes leicht gewulstet, in der hinteren Hälfte völlig glatt. Die Krypten sind offenbar verkümmert. Die für Chrysis gegebene Zeichnung könnte auch für einen Ichneumon gelten.

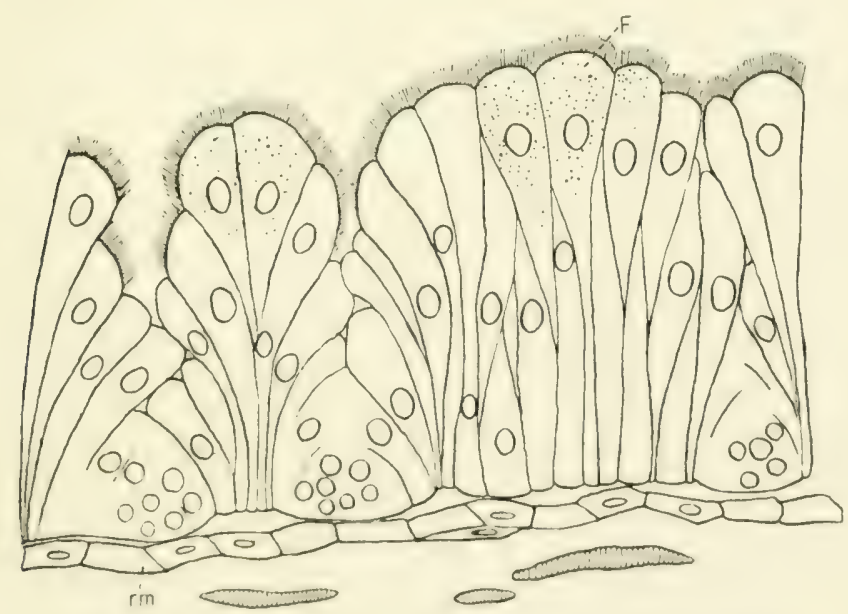

'lextfig. 8. Allantus spec. Lüngsschnitt. Fettresorption. 
Tenthredinidae.

Allantus. Macrophya (Textfigur 8). Der äußerlich fast glatte Nitteldarm besitzt ein ungemein reich entwickeltes Epithel. Bei keiner anderen Familie der Hymenopteren sind die Zellen so langgestreckt wie hier. Die Lrypten sind unregelmäBig rerteilt, jedoch außerordentlich zahlreich. Die hier am stärksten ansgebildete Ringmuskulatur bildet einen zusammenhängenden Mantel um den Mitteldarm.

\section{Formicidae.}

Camponotus ligniperdus (Tafelfigur 4 u. 5). Schnitte durch den eiförmigen, völlig glatten Mitteldarm ergeben eigentümliche, aber recht instruktive Bilder. Gewöhnlich lassen sich außer den Krypten zwei scharf voneinander getrennte Entwicklungsstufen der Epithelzellen unterscheiden: Randzellen mit kömeligem Plasma und häufig undentlichen Zellgrenzen, und Zellen von mittlerer Entwicklung mit streifigem Plasma, die das Lumen des Darmes noch nicht erreichen. Adnerz hielt diese letzteren für resurptionsfühig und die Randzellen für sekretorisch, wir werden sehen, daß nur tie Randzellen sowohl Seliretion als Resorption besorgen. Sie nutzen sich dabei augenscheinlich recht schnell ab, worauf sie ziemlich gleichzeitig im ganzen Darm abgestoßen und durch die nummehr herangewachsenen Zellen der zweiten Stufe ersetzt werden. Fs liegen hier also ähnliche Verhältnisse wie bei Hydrophilus vor, von dem Rengel die periodische Abstoßung des gesamten aktiven Mitteldarmepinels beschreibt. Wie lange jede Randzellenlage in Tätigkeit bleibt, konnte nicht ermittelt werden, doch habe ich des Vorgangs an anderer Stelle noch einmal zu gedenken.

Die Randzellen sind von bedentender Gröbe, sie sind über 3 mal so groß als beispielsweise die von Bombus, und laben dementsprechend grobe Kerne. Die Krypten dagegen sind klein und liegen der Basalmembran dicht an. Dies hat eine weitere Besonderheit des Epithels zur Folge: Den auBerordentlichen Größenunterschied der Randzellen- und hryptenkerne und die verschiedene Größe der einzelnen Krypten unter sich, während bei den iibrigen untersuchten Hymenopteren die rundlichen Kryptenkerne unter sich fast gleich groß und nur wenig kleiner als die ovalen Randzellenkerne sind. Die auBerdem untersuchte Formica rufa verhält sich ähnlich; doch ist die 'l'rennung von Randzellen und den halberwachsenen Ersatz- 
zellen und somit die periodische Abstoßung der Randzellen nicht so deutlich wie bei Camponotus.

Zusammenf assung. Mit Ausnahme der Formiciden, die auch hierin ihre Eigenstellung im System der Hymenopteren bekunden. läßt sich die Epithelstruktur der Imagines mit großer Leichtigkeit auf die der tiefststehenden der Klasse. der Tenthrediniden, zurïckführen. Wir lernten für diese ein hochentwickeltes Epithel mit zahlreichen, vielkernigen Krypten und langzylindrischen Randzellen kennen, wie es in recht ähnlicher Weise Periplaneta und die Larven von Aeschna (Vonsow) besitzen. Dem Epithel der Tenthrediniden schließt sich noch am nahesten das der Honigbiene und der Andrenen an, bei den übrigen Apiden konnten wir den Übergang zu immer einfacheren Verhältnissen beobachten. Die Epithelzellen des kurzen, dafür aber reichgewulsteten Nitteldarmes der Hummeln sind kaum von halber Höhe wie die der Bienen, doch sind die Krypten zahlreich und mohlentwickelt. Bei den Anthophoren, Osmien und Nelecta werden die Krypten spärlicher und die niedrigen Randzellenwiilste rücken weiter auseinander. Die Nomadenbienen endlich zeigen ein ähnlich primitives Epithel. wie wir es bei den Chrysididen und Ichneumoniden fanden. Das regelmäßig gebaute vielkryptige, aber ziemlich niedrige Epithel von Halictus wiederholt sich bei den spegiden. Die Pompiliden und Odynerus von den Vespiden nehmen mit ihren langgestreckten Randzellen und nicht eben häufigen Krypten eine Mittelstellung ein. Auffällig ist die starke Reduktion der Krypten im ganzen vorderen Teil des verhältnismäßig sehr langen Mitteldarmes der eigentlichen Wespen. Die abreichenden Terhältnisse bei den Formiciden werden durch eine Betrachtung des Fpithels ihrer Larven verständlich. Während bei den Imagines der Bienen und Wespen an Stelle des larvalen, sehr großzelligen Epithels ein vollkommen anders gestaltetes tritt, unterbleibt diese weitgelsende Änderung bei den Ameisen). Die Größe der Randzellen und ihrer Kerne, die der Basalmembran dicht anliegenden kleinen Regrenerationskerne der Imagines der Ameisen sind Charaktere, die in gleicher Weise dem Epithel ihrer Larven eigen sind.

\section{Der Enddarm.}

1. Der Dönndarm. Dieser vordere 'leil des Fnddarmes ist kurz und gerade bei den Tenthrediniden und Ichmemmoniden, bei den 
ïbrigen Formen ist er in eine schleife gelegt, am längsten (länger als der Mitteldarm) bei den Ameisen. Er beginnt unmittelbar hinter der Einmündung der Malpighi'schen Gefäße mit der sogenannten Prlorusklappe ('T'extfig. 9), die den C̈bertritt der Nahrung reguliert.

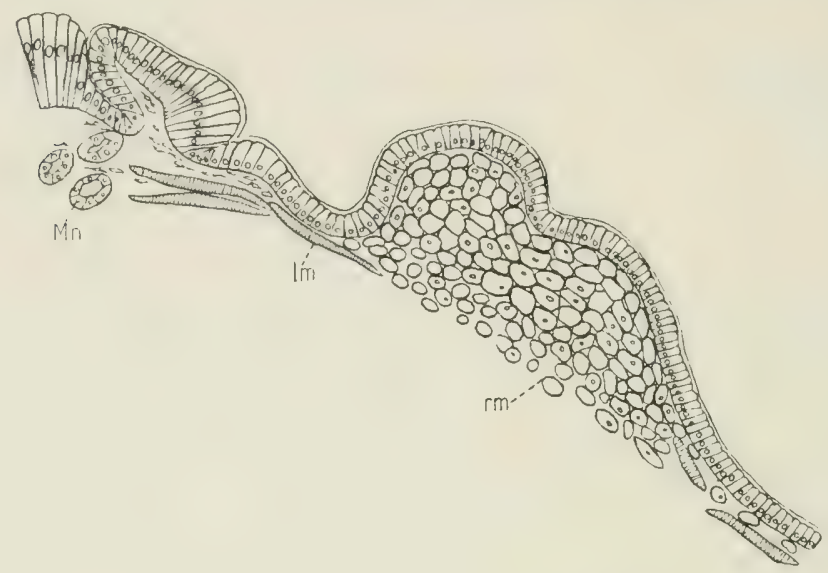

Textfig. 9. Vespa Crabro. Pylorusklappe.

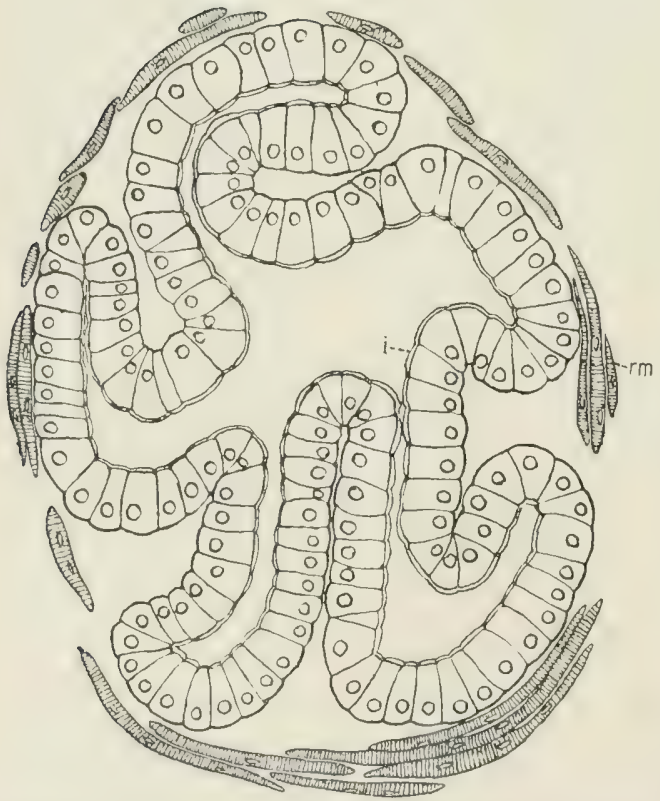

Textfig. 10. Bombus terrestris. Quersehnitt durch den hinteren Teil des Diinndarmes.
Das anfangs gewöhnlich nach vorn eingeschlagene Epithel des Dünndarms verdickt sich an der

Umbiegungsstelle zu einem faltigen Polster, dessen Falten sich bei Kontraktion des etwas weiter hinten gelegenen kräftigen Ringmuskels eng aneinander legen und so einen sicheren Verschluß garantieren. Diese Epithelverdickung fehlt den Ichneumoniden völlig und ist auch bei den 'T'enthrediniden nur schwach. Die Ringmuskulatur ist ïberall über die ganze Länge des 
Dünndarms stark entwickelt, und die einzelnen Fasern sind bedeutend dicker als die des Mitteldarmes. Die Längsmuskulatur dagegen ist mansehnlich. Sie fehlt bei Apis, Bombus, Anthophora gänzlich und ist hier durch Anastomosen der Ringmuskelfasern ersetzt. Nur bei Vespa findet man sie in den für viele Arthropoden charakteristischen 6 Bändern (zu je 3 Fasern) angeordnet. Das Epithel springt in 5 (A pis. Bombus u. a.), 6 (Tespa, Camponotus) oder 7 (Priocnemis) Längsfalten in das Darmlumen vor (T'extfig. 10) und gewährleistet so eine große Erweiterungsfähigkeit. Die einzelnen Zellen sind sechseckig, wenig höher als breit, das Plasma ist streifig, die relativ kleinen Kerne liegen meist anf der dem Lumen abgewandten Seite im Grunde der Zellen. Die chitinige Intima zeigt keine Besonderheiten.

Über die Bedrutung des Dünndarmes lediglich als Verbindungsstiick zwischen Mitteldarm und Rectum (Leuckart) kann kaum ein Zweifel bestehen; denn man findet ihn fast stets leer, und das Plasma der Zellen immer frei von irgendwelchen Einschlïssen oder gar Fetttröpfchen.

2. Das Rectum (Tafelfig. 8). Es ist mit einem lockeren Net\% von Ring- und Längsmuskelfasern überzogen und bildet einen faltigen, außerordentlich erweiterungsfähigen Schlauch. Im leeren Zustande erscheint es über das hinterste Stiick des Dünndarmes. dessen Epithel allmählich in das des Rectums übergeht, umgeschlagen. Das Epithel des Rectums ist flach und läßt im allgemeinen (außer bei den Tenthrediniden) Zellgrenzen nur schwer erkennen. Die Chitinintima ist dünn und nur am Rande der Recta]drüsen verdickt, die hierdurch wie in einer Fassung sitzen. Die Rectaldrüsen der Honigbiene sind von Снск und neuerdings ron Semichox und Petersen beschrieben worden und zeigen in der ganzen Familie den gleichen, aus zwei rerschiedenartigen Blïttern zusammengesetzten Bau. Ihre Bedeutung ist immer noch unsicher. selbst ihre Drüsematur nicht bewiesen. Smarmox hält es für wahrscheinlich, sie seien imstande , de sécréter une matiere... capable dempecher que le paroi du rectum n'absorbe des produits de déchet contenus dans cet organe". Petsisin möchte, vielleicht richtiger. den Nestgernch der Bienen mit ihnen in Zusimmenhang bringen. Die Rectaldriisen fehlen den Hummeln vollkommen: da diese in ihren Lebensbedingungen kaum wesentlich von ihren nächsten Terwandten, z. B. den Bienen oder Anthophoren, alyzuweichen scheinen, glaube ich, daß sie bei den Hymenopteren ïber- 
haupt eine nur untergeordnete Rolle spielen, und dab von hier die Kkärung der Frage nach ihrer Bedeutung nicht erwartet werden darf.

Fast alle Autoren sprechen dem Rectum resorptive Fähigkeit ab und halten es lediglich für ein Kotreservoir. Es wird sich zeigen, dab dies zumindest für einige Hymenopteren nicht zutrifft.

\section{Die Sekretionserscheinungen des Mitteldarmes.}

Der einwandfreie Nachweis, wie eigentlich die Sekretion im Mitteldarm der Insekten ror sich geht, begegnet Schwierigkeiten. die in dem Einfluß der angewendeten Fixierungsmittel anf das Epithel begründet sind. Wo es zur hänfigen Abstobung ganzer Vellen kommt. könnte man annehmen, hauptsächlich diese lieferten bei ihrem Zerfall die unbedingt notwendigen Fermente. So sagt Biederimaxy von der Larve von 'Tenebrio molitor: "Jedenfalls hat man das Recht, den Inhalt des Nitteldarmes im allgemeinen als ein Sekret zu bezeichnen, wobei nur zu berücksichtigen ist. dab die zerstörten Zellkörper selbst einen integrierenden Bestandteil desselben bilden." In den Fällen aber, wo eine solche Zellabstoßung nicht oder nur vereinzelt stattfindet, fragt es sich, ob die Angabe der Mehrzahl der Autoren (Adefrz, Deegener, van Gehuchten, Tornox, Houtz u. a.) zu Recht besteht, nach der es zu einer tropfenförmigen, häufig mit Verlust des Zellsaumes verbundenen Ausstoßung des gebildeten Sekretes kommt, oder ob, wie Vigrox annimmt, die Sekretion als osmotischer Torgang zu denken ist. Tigrox und seine Anhänger, wie Sexichos und I'Etrasex, berufen sich vor allem darauf, dab man durch alle möglichen honservierungsmittel. ja selbst durch blobe Verletzung des frisch untersuchten IIitteldarmes blasenfürmige Ausstülpungen an den Zellen hervorrufen kann. Smirnon mutersuchte den Sekretionsvorgang bei der Honigbiene und einigen anderen Apiden. Petersen ebenfalls den der Honigbiene, und beide kamen, wie auch ich, zu dem Resultat, daß es hier zu einer Ausstoßung gröBerer Sekrettropfen wohl nicht kommt, und also die aus den Zellen ausgetretenen Blasen als Kunstgebilde gedentet werden müssen. Gegen Petersex wendet sich in seiner eingangs erwïhnten Arbeit Steuner, der die 'Theorie Vicinon's allein schon durch die Befunde DeEgExEr's widerlegen zu können glanbt. Ganz abgesehen davon, daß sich der Vorgang von Fall zu Fall verschieden abspielen mag, halte ich seine Beweisführung: „Es sei nicht zn erklären, wartum die Kunstblasen nicht erscheinen, wenn das betreffende Tier, wie es DeEgener machte, während des Fressens 
getötet, im übrigen aber ganz derselben Behandlung unterworfen wurde wie bei solchen Tieren, deren Epithelien dann die Blasen zeigten", für nicht ganz einwandfrei; denn es könnte ja vielleicht anch sein, daß eben der frisch verzehrte Inhalt des Darmes bei Behandlung des Epithels mit Fixierungsmitteln das Frscheinen der Tröpfchen rerhinderte. Dab die Sekretblasen, wie sie sich auf Schnitten zeigen, teilmeise renigstens hunstprodukte sind, gibt übrigens streudeL, wie ja auch kaum anders möglich, zu, da er sie an Resorptionszellen des Wespenmitte!darmes fand, wo sie nach seiner Theorie von der scharfen zeitlichen 'Trennung der Sekretion und Resorption nicht hätten sein dürfen. Er setzt sich aber ïber die entstehende Schwierigkeit. wieviel nun eigentlich Natur und wieriel Kunstprodukt sei, Jeicht hinweg, da es ..seines Erachtens durchaus verstandlich ist, daß Zellen, die durch Reizung zum Ausgieben eines Teiles ihres Inhaltes reranlabt werden, einen Anblick bieten, der dem der sezernierenden Zellen in vielen Punkten gleicht". Mit Sekret gefüllte Zellen werden aber wahrscheinlich noch leichter ..gereizt" werden kömnen und so zu unrichtigen Bildern Anlab geben.

Steuder unterscheidet, wie die meisten Autoren, zwischen ruhendem und sezernierendem Eipithel. Das Sekretionsstadium ron Periplaneta beschreibt er folgendermaken: ...I an sieht auf den ersten Blick, daf das Epithel sein Aussehen durchaus geändert hat. Die leichten Faltungen sind nicht mehr zu erkemnen. Der stäbchensaum ist rerschwunden. Die (Oberflïche des Epithels, dessen Zellen viel länger erscheinen, ist ganz unregehmäbig, an verschiedenen Stellen ist seine Grenze iiberhaupt nirht mit sicherheit festzustellen, da hier Sekretblasen, die noch mit dem Epithel in Zusammenhang standen. platzten, und ihr Inhalt sich mit dem fein granulüsen Darminhalt, der wohl im wesentlichen ans Sekret besteht. mischte. Das Plasma ist schwerer fiubbar: die für das "Ruhestadium" typischen Plasmaanhäufungen sind mit Ausnahme weniger stellen. die sich noch nirht ganz in voller Sekretionstätigkeit befunden. verschwunden. Anstatt dessen ist es jotyt meist schwach gefoirbt. zeigt unregehäbige Netzstruktur und enthält namentlich gereen das Lumen hin zahlreiche gröbere und kleinere steketrakuolen. Besonders in den basalen T'eilen der zellen ist ron Färbung fast nichts mehr zu sehen. da hier die Maschen der Netzstruktur sehr grob sind. Auch die Kerne haben sich verïndert. Sie sind gröber geworden und haben oft eine etwas unregelmäbige fiestalt angenommen. Ihr Chromatin. das sonst ziemlich gleidnmäbie verteilt ist. 
That sich zum grißten 'Teil an dem dem Lumen zugekehrten Pol dicht angesammelt, so daß hier der Kern meistens etwas ausgebuchtet erscheint. Vielfach sind auch die Zellgrenzen mehr oder weniger stark verwischt."

Da die zu dieser Beschreibung gegebenen Zeichnungen mich lebhaft an manche meiner Schnittbilder, deren "Sekretion" ich unbedenklich auf Rechmung der schlechten Fixierung setzte, erimnerten. und um ïberhaupt ein Vergleichsmaterial zum Sekretionsvorgang der Hymenopteren zu haben, nahm ich Gelegenheit, einige der Versuche Steudel's zu wiederholen. Streuder hatte, um die sezernierende Tätigkeit des Epithels zu illustrieren, den Tieren organische Eisensalze oder Kongorot in die Leibeshöhle injiziert. Er fand eine Exkretion des Fisens in den Blindsäcken des Mitteldarmes; bei Injektion von Kongorot erschienen in den Zellen der Coeca, des Mitteldarmes und des Enddarmes rote Takuolen resp. der Farbstoft hatte den basalen Teil des Epithels diftus gerötet. Während dieser Zeit sah er den beschriebenen Sekretionszustand verwirklicht. Ich beschränkte mich auf Injektion von Ferrum lacticum in die Leibeshöhle von einigen 20 Schaben und tötete die Tiere nach 2. t, 5) 8, 10. 20 und 30 Stunden ab. Da mir die zum Eisennachweis nötige Fixierung des Darmes mit ammonsulfidhaltigem Alkohol nicht genügend einwandfrei erschien, konservierte ich jedesmal zur Kontrolle ein anderes gleich behandeltes Tier oder die eine Hälfte des Mitteldarmes desselben 'Tieres mit Alkohol-Sublimat-Salpetersïnre. Die Schnitte des letzteren Iaterials wurden mit Hämatoxylin, die auf Eisengehalt zu untersuchenden je zum 'Teil ebenso gefärbt, den anderen mit Ferrocyankali-Salzsiure behandelten 'Teil ließ ich mngefärbt oder färbte nur wenig mit Boraxkarmin nach.

Es muß nun im voraus bemerkt werden, daß ich bei den injizierten Tieren Eisen zwar im Lumen des Mittel- und Enddarmes und in den Zellen des Enddarmes, wobei dahingestellt bleiben mag; ob es sich hierbei nur um das ,physiologische" Eisen handelte, welches das Enddarmepithel der Schaben enthält, aber niemals in den Zellen der Coeca nachweisen konnte. Da aber die anoefertigten Schnitte die verschiedenen Stadien der Sekretion zu verfolgen erlaubten, ging ich den Ursachen, weshalb das nach Steudel's Tersuchen wenigstens in den /ellen der Coeca doch sicher enthaltene Eisen nicht sichtbar gemacht werden komnte, nicht weiter nach. Enthalten mußte es auch deshalb in den Zellen sein. Weil bei den in den ersten Stunden nach der Injektion getöteten 'Tieren die ITenge des im Darmlumen befindlichen je nach dem Sekretionszustand 
schwankte. Es bleibt der Einwurf übrig, ich hä̈tte zufällig die Stadien der "Eisensekretion" nicht angetroffen; man miißte aber dann für den Durchtritt des Eisens durch das Epithel eine außerordentlich kurze Zeit ansetzen, und dies scheint mir nach meinen Untersuchungen durchaus unannehmbar.

Naturgemäß bekam ich besonders bei den in den ersten Stunden nach der Injektion getöteten Tieren recht wechselnde Sekretionsstadien; doch hatte ich die Schaben absichtlich vorher nicht längere Zeit hungern lassen, da ich die sekretion unter normalen Bedingungen beobachten wollte, und die Schaben sind so gefräßig; daß man sie eigentlich immer mit prall gefülltem Kropfe antrifft. Ein nach 2 Stunden getötetes Tier, das auf Eisen untersucht wurde, zeigte bei stark vakuolisiertem Darmepithel und schlecht erhaltenem Stäbchensaum bereits eine deutliche Blaufärbung der peritrophischen Membran. Bei einigen anderen nach $t$ und 5 stunden $a b$ setöteten Schaben lieb sich Eisen im Darm noch nicht nachweisen. In diesen Fällen befand sich das Epithel im „Ruhestadium“. d. h. der Stäbchensaum war fast überall unversehrt, Vakuolen und ans den Zellen ausgetretenes Sekret fehlten nicht völlig, waren aber selten. Der Darminhalt von nach 8 und mehr Stunden untersuchten Tieren war ausnahmslos eisenhaltig. die Epithelzellen enthielten mehr oder weniger zahlreiche Vakuolen, der Stäbchensaum war erhalten. Wie bei den Versuchen Stevder's war nach 20 Stunden der Mitteldarminhalt am stärksten eisenhaltig, der Inhalt des Enddarmes manchmal ganz gleichmäBig gebläut. Finige Male traf ich anch die Stadien an, in denen sich anf einer gröberen strecke des Mitteldarmes das sekret eben ins Darmlumen ergoß. in einem Falle waren die Sekretrakuolen eben abgestohen worden und noch im lumen zu sehen. Dabei fehlte der Stäbchensaum an manchen Stellen rollkommen, an anderen schien er gerade wieder rückgebildet zu werden.

Man kann also nicht daran zweifeln. dab es bei Periplaneta zu einer bläschenförmigen Ausstobung des sekretes kommt. und meine Befunde bestätigen in dieser Hinsidht die shohlderung STrubrs enteprechen aber seiner I)arstellung von der sckretion nicht röllig. lch konnte nicht finden, dab das byithel dabei wirklich sein Aussehen völlig ändert. Nanche der mit ammonsulfidhaltigem Alkohol behandelten Präparate ähnelten allerdings den Bildern strinsis: d. h. das Epithel lieb tatsïchlich Zellgrenzen nur schwer erkennen, die Kerne waren etwas deformiert, ihr C'hromatin war an die dem Lumen zugekehrte Seite gedrängt und der stïbchensanm fehlte. 
Nit Alkohol-Sublimat-Sajpetersäure fixierte Därme, die sich oftenbar in gleichen Sekretionsstadien befanden, belehrten aber, daß eine so starke Deformierung nicht stattfindet; denn Schnitte von diesem Material ließen stets deutliche Zellgrenzen erkennen, auch wemn die Sekretvakuolen ihren Inhalt in das Darmlumen ergossen. Die Terlagerung des Kernchromatins zeigte sich häufig in gleicher Weise bei typischen Ruhestadien und muß deshalb wohl als Kunstprodukt erklärt werden. Die von STEudel gezeichneten, vollkommen deformierten Kerne sah ich nirgends. Eine Vergrößerung der Kerne während der Sekretion konnte ich nicht beobachten, wohl aber eine Verlängerung der Zellen. Fast unmittelbar unter dem Stäbchensamm liegende Kerne, wohl von zur Abstoßung reifen Zellen, fand ich auch bei ruhendem Epithel ziemlich häufig, manche Schnittbilder konnten aber sogar den Anschein erwecken, als rückten die Kerne während der Sekretion etwas gegen das Lumen vor.

Steudel glaubt bewiesen zu haben, dab nur das ruhende Epithel resorptionsfähig sei. Es ist ja nun fast selbstverständlich, dab während der offenbar nur kurze Zeit beanspruchenden Ausstobung des Sekretes nicht resorbiert werden kann. Auf diese Stadien scheint sich aber STECDEL \%u beziehen; wenigstens sagt er bei Besprechung seiner Injektionsversuche: „Bei einem Tier, das 5 Stunden nach der Injektion getötet wurde, hatte ich das Glück, die Zellen nach eben begonnener Sekret bereitender Tätigkeit anzutreffen. Die Art, wie das Eisen in den Zellen enthalten ist, verleiht ihnen ein sehr überraschendes Aussehen. Die vorderen Teile der Falten (die ältesten, im Stadium am weitesten fortgeschrittenen Zellen) sind ïber und über mit Eisen erfïllt. das sich teils in Form großer runder blauer Punkte, teils in Form ganz feiner, kaum unter Immersion als solche erkenntlicher Pünktchen zeigt." Oftenbar ist aber in diesem Zustand die Bildung des Sekretes bereits vollendet. Nach physiologischem sprachgebrauch hat freilich STEudeL recht, ich möchte hier aber einige Worte van GrHuchten's einfügen. Dieser Autor sagt bei Behandlung des Sekretionsmechanismus im Nitteldarm von Ptychoptera: „Les physiologistes en effet appellent sécrétion l'acte par lecpuel une cellule glandulaire se débarasse des produits accumulés dans son sein, et ils donnent le nom d'excrétion à l'acte par lequel les produits de sécrétion accumulés dans la cavité glandulaire sont conduits à l'extérieur. Dans ces conditions, un organe complexe seul peut í la fois sécréter et excréter tandisque pour une cellule glantulaire isolée on une glande unicellulaire, la sécrétion se confond avec l'excrétion. Et comme le mot de sé- 
crétion s'applique tout simplement a l'expulsion (active ou passive) des produits élaborés dans la cellule, on en est arrivé à cette situation bizarre: d'appeler cellule glandulaire au repos, une cellule qui élabore dans son sein les produits à éliminer, et qui est par consequent en pleine activité pour ce qui concerue sa fonction spéciale de sécrétion, et cellule glandulaire active une cellule gorgée des produits élaborés et qui n`a plus que s’en débarasser d'une façon souvent entièrement passive. C"est lit une situation regrettable."

Daß das Ejpithel während der Bereitung der Sekrete nicht resorptionsfähig ist, hat STEUDEL nicht bewiesen. Fr fand es zwar während der Absorption von eisenhaltiger Nahrung im „Ruhestadium", da er aber dieses zu weit fabt, geht fïir unsere Frage wenig aus seinen Versuchen hervor. In seiner Beschreibung des Ruhestadiums: „Das Epithel der Coeca und les Mitteldames besteht aus hohen Zylinderzellen, die zu kleinen Falten angeordnet sind. Das Plasma ist nach (lem Lumen zu stark verdichtet, ${ }^{1}$ ) die ovalen Zellkerue sind regelmäßig angeordnet, die Oberfiache ist kontinuierlich nnd dnrchweg von einem stäbchensaum eingefaßt", vermisse ich vor allem eine Angabe über Takuolenbildung. Er beschreibt zwar die Resorptionsvaknolen, in denen das kisen vorzugsweise enthalten ist, sagt aber von eventuellen vekretionsrakuolen nichts. Ich sah auch auf Schnitten ron typischen Ruhestadien stets hier und da Zellen, die rekret enthielten resp. in das Darmlumen ergossen, und es scheint mir bedenklich, diese Bildungen etwa fïr künstlich zu erklären.

Zur Untersuchung des Sekretionsrorganges bei den Hymenopteren erweisen sich die meisten Fixierungsmittel als untauglich. und man muß sich häufig auf Beobachtungen am frisch aufgeschnittenen Darm beschränken. Schnitte von konserviertem Material ergeben oft Bilder, die eine auberordentlich starke ..'sekretion“ vorzutäuschen imstande sind. Aber schon die Verschiedenheit dieser Psendosekretionserscheinungen bei Anwendung der einzelnen Fixierungsmethoden rät zur Vorsicht. Bei Anwendung ron Flemming'scher

1) Diese Plasmaverdichtung ist sichtlich durch die einseitige Einwirkung der Fixierungsmittel hervorgerufen. Sie als Charakteristikum des Ruhestadiums hinzustellen ist schon deshalb unzulissig, dat sich das gleiche Verhalten, wenn vielleicht auch wegren der Vakuolen nicht so augenfillig. bei sezernierendem Elithel, sogar auf einer Zoichnung STELDLL's, nachweisen liißt. 
Lösung sind die neben den Krypten gelegenen Zellen gleichsam zerflossen (Tafelfigur 1), so daß eine scharfe Grenze des Epithels nicht $\mathrm{zu}$ sehen ist, während bei Anwendung von Sublimat-AlkoholSalpetersäure dieselben Zellen ebenfalls ihren oberen Teil, aber in Gestalt eines scharf umgrenzten Tröpfchens, abgestoßen haben. Bei Untersuchung von Schnitten durch den Wespendarm zweifelte ich anfangs nicht, es wirklich mit tröpfchenförmiger Sekretion zu tun zu haben. Man sieht, wie aus den Zellen Bläschen austreten, die langsam größer zu werden scheinen, aber noch durch einen Stiel mit der Zelle verbunden sind (Textfigur 5). In weiteren Stadien werden diese Tröpfchen abgestoßen, der ganze obere Teil der Zelleu verliert seine Form, die Zellgrenzen sind nur undeutlich sichtbar und unregelmäßig, die Kerne deformiert, der Stäbchensaum fehlt. Gewöhnlich zeigen die dem Lumen am weitesten zugekehrten, ältesten Zellen bei erhaltenem Stäbchensaum und sonst guter Konservierung die kleinen Ausstülpungen, während sich die im Grunde der Ringwülste liegenden Zellen im gleichen Darm in lebhafter "Sekretion" befinden. Höchstwahrscheinlich handelt es sich aber hierbei um reine Kunstprodukte, die in der großen Fmpfindlichkeit besonders der jugendlichen Zellen ihren Grund haben. Dafür spricht, daß Schnitte durch den Mitteldarm von eben vor dem Ausschlüpfen stehenden Wespen (und Bienen) desgleichen ron einem zu Anfang des Dezember im Winterschlaf gefundenen Wespenweibchen die gleichen Erscheinungen darboten; die Untersuchung des frisch aufgeschnittenen Darmes vollends verschafft Gewißheit, daß es zumindest nicht zu einer Deformierung der Zellen kommt, denn die meist sechseckigen Zellgrenzen sind auch im Grunde der Ringwülste dentlich zu sehen. Die Obertläche des Epithels erscheint ebenfalls unversehrt, doch ist eine sichere Beobachtung bei dem kleinen Durchmesser der Zellen schwierig, zumal sich regelmäßig auch bei dem in seiner eigenen Flüssigkeit untersuchten Darme nach kurzer Zeit eine Quellung der jüngeren Zellen einstellte.

Rungios beschreibt Sekretbildung im Hals der Kryptenschläuche bei Dytiscus marginalis, und die dort sezernierenden Zellen entsprechen den jüngeren, neben den Kirypten liegenden Zellen der Hymenopteren. Der schlechte Lrhaltungszustand gerade dieser Zellen könnte zu der Annahme führen, es liege etwas ähnliches auch bei den Hymenopteren vor. Da ich aber bei den Tenthrediniden, bei denen die betreftenden Zellen meist gut erhalten sind, und bei den Ameisen, bei denen sie nicht bis ans Lumen reichen. Sekret nder Vakuolen in ihnen nicht finden komnte, glaube ich ohne zwingen- 
den Grund eine derartige Sekretbildung auch für die übrigen Hymenopteren nicht annehmen zu dürfen.

Die Randzellen des Mitteldarmepithels der Hymenopteren enthalten mehr oder weniger reichlich lichtbrechende, rundliche Körperchen, die Frexzel'schen "Sekretkugeln". Ihre Konservierung ist leider schwierig, da sie sich in Säuren lösen und auch bei bloßer Alkoholbehandlung nicht immer erhalten bleiben. Eigentiumlicherweise fand ich sie einige Male auf Präparaten, die kurze Zeit (etwa ${ }^{1 / 4}$ Stunde) mit Sublimat-Alkohol-Salpetersäure behandelt worden waren, erhalten. Biederasx möchte sie als Speichermaterial auffassen, es ist aber nach den Untersuchungen Semicuos's nicht zweifelhaft, dab man es hier wirklich mit dem geformten Sekretdes Mitteldarmes zu tun hat. Sемıном untersuchte die Honigverdanung im Hummeldarm und kam inbetreft der Sekretkugeln zu folgendem Resultat: „Les cellules en massue, qui couromnent les rides de l'intestin moyen elaborent un-produit de sécretion, aftectant l'apparence de grains refringents. Ceux-ci ne sont pas expulsés d'un seul coup ainsi que certains fixateurs pourraient le faire croire. En face des cellules et à leur voisinage immédiat, le miel est parsemé de grains semblables à ceux qu'elles contiennent, ils deviennent de moins en moins nombreux dans celle-ci à mesure que la digestion s'avance." Und ganz ebenso sagt er ron der Honigverdaumg der Drohnen: „La diminution des grains dans les cellnles est graduelle et parallèle a la modification du miel." Ich vermochte diese diffizilen Untersuchungen nicht einwandfrei nachzuprüfen, kamn aber eine am Mitteldarmepithel von Camponotus gemachte Beobachtung mitteilen, die ganz den Befunden Sexicuox's entspricht. Läbt man Arbeiter oder Weibchen von (amponotus längere Zeit, zumindest \& Tage, hungern, so wird die alteste Zellschicht des Mitteldarmepithels völlig abgestoBen, und während sich die Regenerationszellen nur wenig vergrößert haben, ist die mittlere Kellschicht zu der Größe der ältesten herangewachsen. Diese nummehrigen Randzellen sind gleichmäßig mit Sekretkugeln gefüllt, die nach Fixierung des Elithels ihre Spuren in Gestalt einer regelmäbig netzförmigen struktur des Plasmas hinterlassen. Das Ejpithel ron 'Tieren ohne Hungerzeit zeigt diese Netzstruktur gewohnlich nicht, ohgleich die Zellen ganz sicher Sekretkugeln enthielten, und es lingt nahe, den Girmul dafür in den dann noch in den \%ellen enthaltenen Absorptis zu suchen. Fïttert man nun Hungertiere mit fetter Mildh und untersucht man das narh 10-15 Stunden mit Fumuxcischer löstng konservierte, in Resorption betindlide Mitteldarmepithel. so erhailt 
man Bilder, von deren Aussehen 'Tafelfig. 7 eine Torstellung zu geben versucht. Das Plasma ist schwer färbbar, die Kerne sind deformiert, der Stäbchensaum nicht überall erhalten, Zellgrenzen sind kaum erkemnbar. Kurz, man möchte glauben, es mit einem ausgesprochenen STEUderischen Sekretionsstadium zu tun zu haben. Dabei sind die Zellen in voller Resorption, wie die Menge der in ihnen enthaltenen Fettröpfchen beweist. Soweit aber, und nur soweit die Zellen mit diesen Tröpfchen erfüllt sind, ist die gleichmäßig netzförmige Plasmastruktur verschwunden oder wenigstens so vergröbert, daß sie der Größe und Verteilung der Sekretkugeln durchaus nicht mehr entspricht. Dies Verhalten ist das gleiche, wie es Smurion beobachtete: Die Sekretkugeln verschwinden nach Maßgabe der fortschreitenden Resorption. In welcher Weise sich der Vorgang abspielt, ob, wie Senrchor für die Apiden angibt, die Sekretkugeln als solche ausgestoßen, oder ob sie noch imnerhalb der $/ 2$ elle aufgelöst werden, konnte freilich nicht klargestellt werden.

Im AnschluB an die Sekretion muß auch der viel erörterten peritrophischen Membran, die den Mitteldarminhalt vieler Insekten umkleilet, gedacht werden. Die Mehrzahl der Autoren lält sie für ein Schutzorgan für das Epithel, Bercese nennt sie einen Dialysator, der zwar Peptone durchließe, Albuminen aber den Durchtritt verwehre. Die Angaben iiber ihre Herkunft sind verschieden. Plateau, Frenzel, Schiemenz und Petersen, die sie bei Hymenopteren untersuchten, hielten sie für ein Produkt der Zellen des ganzen Mitteldarmes, Schientexz gibt sogar an, anf ihr die $\downarrow$ bdrïcke der eimzelnen /sellen gesehen zu haben. VAN Genuchten (Larve von Ptychoptera contaminata), Bordas (Raupe von Jo Irene) 11. a. stellten als ihren Ursprungsort eine besondere Zellschicht im vorderen T'Teil des Mitteldarmes fest, und BerLess, der sie bei der Imago von Calliphora untersuchte, glaubt diese Befunde verallgemeineru zu diufen. Gleicher Ansicht ist auch Smuchon, der von der peritrophischen Membran der Bienen sagt: „Il importe de distinguer de la membrane peritrophique vraie dont l'existence se constate par rivisection, les membranes illusoires que lon rencontre dans les coupes et qui résultent de la précipitation de differentes matières, par le fixateur... Il est possible aussi que la matière qui la constitue, sécrétée autour de la partie pendante de la Talvule cardiaque, s'éconle en plus grande aboudance au moment ou le pollen franchit cette valvule." Trenn es nun auch sicher ist, dal. viele der ,peritrophischen Membranen“, die man besonders an mit Irmmaxisher Iösung konserviertem Material zu sehen be- 
kommt, als Kunstgebilde erklärt werden müssen, konnte ich mich doch ron einem solchen Ausflieben der Membran rom oberen Teile des Mitteldarmes nicht überzeugen. Man miibte doch erwarten, daß die zu dieser enormen Absonderung bestimmten Zellen irgendwie vor dem übrigen Epithel differenziert wären; davon zeigten aber die mir vorliegenden zahlreichen Längsschnitte durch den oberen Teil des Mitteldarmes der untersuchten Hymenopteren nur recht menig. Allerdings fällt vor allem bei Bienen und Hummeln der erste Epithelwulst, von dem die peritrophisehe Membran ihren Anfang nimmt, durch das dichtere Plasma und die deshalb stärkere Färbbarkeit der Zellen etwas auf: da die Zellen sich aber sonst nicht weiter von denen des übrigen Epithels unterscheiden und auch einen Stäbchensaum besitzen, kann ich mich nicht entschließen, sie allein fïr die Bildung der peritrophischen Membran rerantwortlich zu machen. Andererseits findet man tatsächlich auch bei frisch untersuchten Bienen und Wespen nicht nur eine, sondern mehrere derartiger Membranen. Besonders bei Wespen (aber auch bei Bienen) setzt sich die peritrophische Membran, während sie im vorderen Teile des Mitteldarmes manchmal rollkommen fehlt, in seinem hinteren Teile häufig aus vielen, ziemlich regelmäßig übereinander angeordneten Lagen zusammen. Dab sie im rorderen Teile des Darmes fehlen kann, besagt allerdings nichts; aber wie will man sich die Übereinanderschiebung der schlauchförmigen Häntchen, bei der die jüngeren über die älteren zn liegen kommen, erklären, wenn sie wirklich nur von einem im vorderen. bei Wespen viel dümneren IIitteldarmabschnitt gelegenen Epithelring gebildet wïrden? RExGeL nennt die peritrophische Membran ,.eine wahre Intima", mit der sich die Zellen während der liuhepansen umkleiden sollen, und meine Befunde an der Larve von ('amponotus scheinen die ebenfalls vertretene Ansicht zu bestitigen. dab in manchen Fällen die abgestobenen stäbchensïume Anlab zu ihrer Bildung geben. Für die Imagines, besonders der mit reich gewulstetem Mitteldarm anscestatteten Furmen. triffit dies aber sicher nicht zu, da man sonst. Woyon nichts zu bemerken, Membranen von recht grober Lngleichmäbigkeit erwarten mübte. Vielmehr scheint mir die Leichtigkeit. mit der durch Reagentien membranartige Bildungen im Mitteldam hervorgerufen werden, darauf hinzudenten. dab es sich dabei un die Vergröbermg eines nomalen Vorganges handelt; und es bleibt für mich mur die Ammahme iibrig, die peritrophische Ifembran komme durch die (saures Reaktion des 
in den Mitteldarm iibertretenden Kropfinhaltes auf das (alkalische) Mitteldarmsekret aus diesem zustande.

Wie alle Beobachter fand ich die peritrophische Membran meist nur bei mit fester Nahrung gefülltem Mitteldarm ausgebildet. Sie fehlt den Imagines von Camponotus und Formica völlig, desgleichen rermißte ich sie bei Chrysis und den Sphegiden, deren Darm keine feste Nahrung enthielt. Bei den untersuchten Ichneumoniden, auch wenn sie einige wenige Pollenkörner gefressen hatten, und den Tenthrediniden, deren Darmkanal fast stets prall mit fester Jahrung gefuillt ist. zeigte sie sich so schwach entwickelt, daB ich nicht sicher bin, ob es sich vielleicht nicht um bloße Kunstgebilde handelte.

Zusammenfassung. Ich komme betrefts der Sekretionsvorgänge zu folgendem Resultat: Die Sekretion verlüuft bei Periplaneta, ähnlich wie bei den Larven von Aeschna (Torxow) und Dytiscus (Rungus), in der Weise, daß in den Zellen Vakuolen gebildet werden, die sich unter gleichzeitiger Vergrößerung dem freien Rande der Zellen nähern. Bei der Ausstoßung dieser Sekretvakuolen verschwindet der Stäbchensaum. Die von Steudel beobachtete starke Deformierung les Epithels während der Sekretion vermochte ich nicht festzustellen. Versteht man wie SteddeI unter sezernierendem Epithel nur solches, das eben seine Vakuolen ausstößt oder auszustoßen im Begriff ist, so wird sich gegen die behauptete Resorptionsunfühigkeit während der Sekretion kaum etwas einwenden lassen, da ja der Darminhalt durch das nach außen drängende Sekret rom Epithel getrennt ist. Da ich aber wie van Genuchtex die offenbar nur kurze Zeit beanspruchende Ausstoßung des Sekretes, nach der sehr bald ernente Vakuolenbildung einzusetzen scheint, nur als den Schlubakt der Sekretion auffasse, kann ich mich nicht dizu verstehen, eine scharfe Grenze zwischen ruhendem, resorptionsfühigem und sezernierendem, resorptionsunfähigem Epithel anzunehmen.

Der Sekretionsvorgang der Hymenopteren läbt sich mit lem von Periplaneta nicht vergleichen. Vaknolenbildung in den Randzellen konnte in keinem Falle festgestellt werden. Ob die neben den Krypten gelegenen, halberwachsenen Zellen in einigen Fällen in der von Rungius für Drtisens beschriebenen Weise sezernieren, vermag ich nicht mit Sicherheit zu verneinen, doch würde diese Art der Sekretion, auch wenn sie wirklich stattfände, eine sicher mur untergeordnete Rolle spielen. An der Bedeutung der in den liandzellen enthaltenen lichtbrechenden Körper als Sekretkugeln kamn meines Erachtens nicht gezweifelt werden. Da diese wïhrend 
der Resorption verschwinden, halte ich mich für berechtigt, mit Semrchon den Satz zu vertreten: Resorption und Sekretion sind in den Randzellen des Mitteldarmepithels der Bienen und Ameisen (die ibbrigen Hymenopterenfamilien konnten daraufhin nicht untersucht werden) nicht zeitlich vollständig getrennte Prozesse, sondern die gleichen Zellen enthalten sowohl Sekrete als auch Absorpta, mnd zwar je mehr Sekrete desto weniger Absorpta und umgekehrt.

Für die Entstehung der peritrophischen Nembran schließlich mache ich bei den Hymenopteren nicht allein einen im vorderen 'Teil des Mitteldarmes gelegenen Epithelring, sondern das gesamte Epithel des Mitteldarmes verantwortlich. Bei den Larven von Camponotus geben sehr wahrscheinlich die abgestoßenen Stäbchensäume Anlaß zu ihrer Bildung, bei den Imagines halte ich sie für ein Koagulationsprodukt der zerflossenen Sekretkugeln.

\section{Versuche zur Fettresorption.}

Apis mellifica. Petersex untersuchte die Verdaung bei der Honigbiene und verfüterte unter anderem auch angesiißte Ölemulsionen. Eine Resorption des Fettes konnte er in keinem Darmabschnitt nachweisen. Leider erschien seine Arbeit erst nach Abschlug meiner Versuche; denn ich hatte die gleichen Erfahrungen machen müssen. Die Fütterungsversuche leiden unter der Hinfälligkeit der gefangen gehaltenen Bienen. Die im Hochsommer vom Flugloch des Stockes genommenen und in weiten trlasgefäßen oder Holzkästen untergebrachten Tiere starben meist sämtlich bereits nach 2-3 Stunden. Etwas besseren Erfolg hat man mit überwinterten Bienen oder solchen von der letzten Brut. Von diesen hält sich ein gewisser Prozentsatz einige Tage leidlich gut, wenn ihnen Zuckerwasser zur Verfïgung steht.

Da Kontrollversuche den gesamten Darmtraktus dieser (Tracht) Bienen fettrei zeigten, kounte ohne längere Hungerzeit zu Fïtterungsversuchen ibbergegangen werden. Wie l'wTEnswex rerfïtterte ich anfangs angesibite (i)mulsionen. Die Tröpfchen der Emulsion liefen aber bereits im Mitteldarm zusammen und im Rektum befand sich, wenn es iiberhaupt so weit kam. ein einziger grober (iltropfen. In den fypithelien des J)armes war kein Fett nachzuweisen. Ich versuchte ('s deshall) mit fottre. obenfalls etwas angesïßter Milch. Nach versicheden langer /eit wurden die Bienen getötet, lïnger als 12 stunden gelang as mir nie, sie nach der Fitterum am Leben zu erhalten. In den ersten " stunden 
trat nur wenig der im Honigmagen geronnenen Milch in den kollabierten Mitteldarm über. Nach 3 Stunden war der größere Teil der aufgenommenen Milch in den nunmehr prall und durchscheinend gewordenen Nitteldarm gelangt und konnte im unverletzten Darm als scharf abgesetzter, wurstförmiger Körper beobachtet werden. Die später getöteten 'Tiere zeigten dasselbe Verhalten, d. h. weiter als in den vorderen Teil des Dümndarmes gelangte die Nilch nicht. Die Mitteldarmzellen enthielten keine Fetttröptchen ${ }^{1}$ ).

Um etwaige Störungserscheinungen, die sich aus dem Gefangenhalten der Bienen ergeben könnten, zu vermeiden, rerabreichte ich einem ganzen Bienenstocke an 2 aufeinanderfolgenden Nachmittagen je $1 / 2$ Liter lauwarme, etwas angesiißte fette Milch. Es geschah dies zu Anfang des September, und aus der Stiilpflasche, in der die Milch gegeben wurde, war an den vorhergehenden Tagen Zuckersaft verfüttert worden. Die Bienen verzehrten aber bis zum nächsten Morgen nur je ungefähr $10 \mathrm{ccm}$ der Flüssigkeit, und im Darm der untersuchten Exemplare war nichts davon zu finden. Angenscheinlich hatten sie die Milch überhaupt nicht bis in den Mitteldarm kommen lassen, sondern sie in die Waben ausgebrochen: demn bei der späteren öffnung des Stockes zeigte sich eine ganze Reihe der Honigzellen mit eingetrockneter Nilch gefüllt.

Die mit einer ihnen mmatürlichen Liost gefütterten Bienen erweckten also den Anschein, als sei ihr Darm zu einer Fettresorption nicht imstande. Wahrscheinlich waren aber nur die einzelnen Trüpfchen selbst einer so feinen Emulsion wie der Vilch für die Verdaumossekrete ihres Mitteldarmes zu groß; denn das im Pollen ganz außerordentlich fein verteilte Fett vermögen sie recht wohl zu verdanen. Allerdings muß man, um dies festzustellen, Bienen aus dem Stock, am besten von den Brutwaben nehmen. Diese enthalten bei gewöhnlich leerem Kropf meist ansehnliche Mengen Pollen im Nittel- nnd Enddarm. Die im Mitteldarm befindlichen Pollenkörner sind teils unversehrt, teils haben sie ibren durch Os-

1) Leider ist der Erhaltungszustand des Epithels gerade bei Bienen nach Milchfütterung ein außerordentlich schlechter. Selbst wenn es zu einer, wenn auch sicherlich geringen Fettresorption käme, würde man diese kaum nachweisen können, da die freien Ränder der Zellen mehr oder minder zerflossen sind. $\mathrm{Ob}$ diese Erscheinung möglicherweise damit zusammenhängt, daß die im Kropf sauer gewordene Nilch eine vielleicht übermäßige Sänerung des Mitteldarminhaltes bewirkt, die das Epithel für die Einwirkung der Fixierungsmittel empfindlicher machen könnte, vermag ich nicht zu sagen, halte aber ihretwegen jetzt selbst die Milchfütterung bei Bienen für verfehlt. 
mium stark geschwärzten Inhalt austreten lassen. Ein verhältnismäßig kleiner Teil des Pollenfettes wird ron den Randzellen des Nitteldarmepithels resorbiert. lch komnte diese Resorption stets nur im hinteren 'Teil des Mitteldarmes wahruehmen, am stärksten ist sie in der nächsten Nähe der Eimmündung der Malpighischen Gefäße. Das Fett ist in den Zellen in Gestalt kleiner, unter. sich fast gleich großer 'Tröpfchen enthalten; manchmal so reichlich, daß die Zellen fast gänzlich damit erfüllt sind ('T'af'elfig. 1 u. 2).

Der verbleibende Inhalt des Mitteldarmes tritt durch die Pylorusklappe in den Dünndarm, und zwar in einzelnen Portionen. die durch die Kontraktion des kräftigen, um den Anfangsteil des Dünndarmes lanfenden Ringmuskels abgeschnürt werden. Diese Nahrungsballen erleiden im Dünndarm keine Veränderung und pasieren ihn augenscheinlich recht schnell, da man sie nur selten darin antriftt.

Im Rektum angelangt, lösen sich die durch die Reste der peritrophischen Membran zusammengehaltenen Ballen nicht auf. sondern schwimmen in größerer Anzahl als ungefähr ${ }^{1}$ „_-1 mm dicke Kügelchen in einer schwach gelblichen Flüssigkeit.

Durch die lebhaften peristaltischen Bewegungen des Rektums (die man hier und da an frisch geöffneten Bienen zu Gesicht bekommt) werden sie auf und ab getrieben und verlieren in dem Maße an Tolumen als der Inhalt der Pollenkörner verdaut wird. Denn tatsächlich wird der größere 'Teil des Pollenfettes, und dem Anschein nach auch des Eiweibes, erst hier resorbiert. Während die zuletzt eingetretenen, größten Portionen sich in nichts rom Mitteldarminhalt unterscheiden, also außer vielen unverletzten Pollenkörnern das durch Osmium immer noch stark geschwärzte. scheinbar wenig reränderte ausgetretene spermatoplasma des Pollens enthalten, zeigen die länger im Rektum befindlichen viel weniger unversehrte Körner und eine infolge der schwächeren Osmierung hellere Färbung. Tlie kleinsten. am längsten im Rektum befindlichen Portionen schlieblich bestehen nur noch aus den mit Resten der peritrophischen Membran vermengten, röllig deformierten Pollenschalen. Gleichzeitig häuft sich in den zellen des Rektums eine manchmal erstaunlich grobe Irenge von Fett an ('Tafelfigur 9). so daf die an sich viel breiter als hohen Zellen beträchtlich aufschwellen. War das Rektum bis zum schwinden der Falten gefüllt. so ist mit Ausnahme der Rektaldrïsen häufig kaum eine Zelle fettfrei; bei geringerer Füllung woisen es nur die dem Lumen zunächst gelegenen Zellen auf. (ob und wie weit die auberordentlich reiche Bakterienflora des Rektums, auf die meines Wissens znerst Platrkax 
aufmerksam gemacht hat, die Resorptionsfähigkeit befördert, vermag ich nicht zu entscheiden.

Bei gefangen gehaltenen Bienen finden sich noch nach 2 Tagen unvollstandig verdaute Nahrungsballen im Rektum, doch wird dies den normalen Verhältnissen nicht entsprechen, da die Bienen in der Gefangenschaft nach kurzer Zeit zu fliegen aufhören und völlig ruhig dasitzen, während sie sonst im Fluge zu defäzieren pflegen* Dies könnte eine Verlangsamung des Verdaunngsvorgangs oder gar völlige Sistierung zur Folge haben.

Begreiflicherweise ist der Mai und die erste Hälfte des Juni, also die Zeit der stärksten Brut, für die Beobachtung der Fettresorption am günstigsten. Wie bereits bemerkt, tut man am besten. die Bienen dazu aus dem Stocke zu nehmen und darauf zu achten. daß man die jüngeren Brutbienen vor sich hat. Denn nur bei ihnen findet man mit einer gewissen Regelmäßigkeit den Nittelmnd Enddarm stark mit Pollen gefüllt and in Resorption. Die an den schadhaften Flügeln und der mangelhaften Behaarung meist leicht kenutlichen älteren Trachtbienen haben gewöhnlich, auch wenn man sie aus dem Stocke nimmt, nur wenig Pollen in ihrem Darmkanal und Fetttröpfehen in den Epithelzellen sind selten oder fehlen gänzlich. Die Angabe LEuckart's daß auch die Trachtbienen den Pollen bis auf die Hüllen verdauen sollen, vermag ich nicht zu bestütigen, denn ich fand in ihrem Rektum, wenn es überhaupt Pollen enthielt, stets reichlich unversehrte Kïörner und vermißte vor allem die nur noch aus den Pollenschalen bestehenden Kotballen stets. MIan kann deshalb wohl annehmen, daß die in ihrer Jugend übernährten Bienen für die kurze Zeit ihres späteren Lebens als Trachtbienen nur wenig fett- und stickstofthaltige Nahrung bediirfen und demgemäß auch die Fähigkeit, das Spermatoplasma des Pollens vollkommen auszuniitzen, verloren haben. Hiervon ausgenommen sind die überwinterten Bienen, bei denen ich einige Male im April eine ziemlich bedeutende Resorption beobachten konnte. Beí allen in den Herbst- und Wintermonaten frei gefangenen oder aus dem Stocke genommenen Bienen war eine Fettverdaunng in keinem Falle festzustellen. Das Rektum von im Jannar nach einer längeren Kälteperiode aus dem Stocke genommenen Bienen erwies sich zwar so stark mit einer ziegelmehlähnlichen Masse, den nicht zu einzelnen Ballen vereinigten Pollenkörnern, gefüllt, daß es fast das manze Abdomen einnahm; in den Epithelzellen war jedoch keine sur von Fett nachzuweisen und die Pollenkörner waren meist unrersehrt. Diese Beobachtungen scheinen die Behauptung Küstex- 
IIACHER's, die Bienen könnten überhaupt nur frischen Pollen verwerten, zu beweisen.

Es ist noch hinzuzufügen, daß frisch geschlüpfte Bienen, gleich wie die nur von Honig lebenden Drohnen, ebenfalls niemals Fetttröpfchen in den Zellen des Mittel- oder Enddarmes enthielten.

\section{Bom bus.}

Im Frühjahr wurden Weibchen, im Sommer Arbeiter zu den Fütterungsversuchen verwendet. 24 Stunden ohne Nahrung gehalten, nahmen sie angesïßte Ölemulsionen willig anf. Die Emulsion begann sich, wohl infolge der sauren Reaktion, bereits im Honigmagen zu klären, nach 12-15 Stunden war das Rektum mit klarem Öl gefüllt. Eine Resorption konnte nicht nachgewiesen werden. Nach Milchfütterung erschienen die leidlich erhaltenen Randzellen etwas dunkler als bei ungefiitterten Tieren, doch war es auch bei stärkster Vergrößerung nicht möglich, diese graue Färbung in einzelne Tröpfchen aufzulösen.

Die sofort nach dem Fang getöteten Tiere ließen ebenfalls weder im Mitteldarm noch im Rektum Fettresorption erkennen. Es mag dies wohl damit zusammenhüngen, daß mir nur im Fluge gefangene Hummeln zur Verfügung standen; die im Nest befindlichen dürften sich doch wahrscheinlich nicht anders als die Bienen verhalten.

\section{Vespa.}

Auffälligerweise waren die im Frühjahr fliegenden Wespenweibchen empfindlicher als die Hummelweibchen. Sie vertrugen weder (̈lemulsion noch Milch und gingen regelmäßig 3-6 Stunden nach der Fütterung zugrunde. I (hl wandte mich deshall) an die Arbeiter, von denen im Juli einige 20 unter gleichen Terhältnissen wie die Bienen gehalten wurden. Sie vertrugen die Gefangenschaft gut und nahmen gierig die gereichte Nilch anf, die man bei der 8 und 12 Stunden später erfolgten Präparation wie bei den Bienen und übrigens auch den Hummeln durch den Mitteldarm durchscheinen sah. Gleichwohl fanden sich in den Epithelzellen keine Fetttröpfchen. In Glauben, daß bei den omnivoren Wespen ganz sicher eine Fettresorption nachweisbar sein würde. schob ich die Schuld auf die unnormalen Bedingungen und brachte ein ausgegrabenes, wenig beschädigtes Vespennest mit seinen Bewolnem in einer Kiste unter. Die Wespen grewähten sich schnell an ihren 
neuen Aufenthaltsort, und es wurde ihnen $1 \pm$ Tage lang freier Einund Ausflug gestattet, während welcher Zeit sie sich völlig wohl befanden. Hierauf wurden sie 2 Tage bei Zuckersaft und einen Tag ganz ohne Nahrung belassen. Da sie anfingen, ihre Larven aus den Waben herauszureißen und zu zerbeißen, bekamen sie nunmehr angesuißte Hilch verabreicht. Wie sich zeigte, war das Resultat ebenfalls negativ. Die Tiere hatten sich genau wie bei dem vorhergehenden Versuch verhalten. Sie waren nach 18 Stunden getiitet worden, und der Darmkanal der untersuchten Exemplare zeigte sich mehr oder weniger gefüllt, da ihnen die Milch während dieser ganzen Zeit zur Verfügung gestanden hatte. In einigen Fällen ließ sich hier besonders schön der Öbertritt der Nilch aus dem Mitteldarm in das Rektum verfolgen; der Dünndarm enthielt In gleichen Abständen 8-10 Nahrungsballen. Im Rektum befand sich eine weiße Masse, die sich scheinbar nur durch ihre krïmelige Beschaffenheit von der verfütterten Milch unterschied.

Es geht hieraus hervor, daß die Imagines der Wespen nicht imstande sind, das in der Milch enthaltene Fett zu resorbieren, oder wenigstens, daß etwa resorbiertes Fett durch Osmierung nicht nachweisbar ist.

Um mich ïber den eventuellen Aufbau von Fett in den Darmzellen zu vergewissern, waren andere Wespen einige Tage nur mit Obst gefüttert worden. Die Untersuchung zeigte das Epithel des Mitteldarmes vollkommen fettfrei. Die sehr flachen Kellen des Rektums sind leider nach Behandlung mit Flemming'scher Lösung so schlecht erhalten, daß eine exakte Untersuchung nicht möglich ist.

Da sich das Darmepithel der sofort nach dem Fang getöteten Wespen, bei denen darauf geachtet wurde, daß der Darm gefüllt war, ebenfalls frei von Fetttröpfchen erwies, bin ich nicht imstande, eine Angabe über Resorption von Fett zu machen.

Camponotus ligniperdus.

Von den Ameisen erschien mir der große Camponotus zu Fütterungsversuchen am geeignetsten. Da der beliebig langen Gefangenhaltung nichts im Wege steht und Nahrungsentziehung dank des stark entwickelten Fettkörpers wochenlang schadlos ertragen wird, war von hier ein einwandfreies Ergebnis zu erwarten. Es wurden sowohl Weibchen als Arbeiter verwendet. Ich lieb die There 3-8 Tage ohne Nahrung und brachte ihnen dann gewaltsam 
durch Bestreichen der Mandibehn Öl bei. Der Kropf ron nach j Stunden getöteten 'Tieren war mit klarem öl gefüillt, die Zellen des Mitteldarmes enthielten unter ihrem freien Rande kleine Fetttröpfchen. Bei den nach 10 Stunden untersuchten Tieren war der Kropf meist wieder leer, der Mitteldarm enthielt immer nur wenig Öl, die Hauptmasse fand sich in klarem /ustande im Rektum. Die Mitteldarmzellen waren nicht stärker mit Fettrö̈pfchen erfiillt als bei den nach 5 Stunden getöteten (Tafeltig. 4). Die Resorption war also eine sehr unvollständige, und ich verfïtterte deshalb in der Folgezeit auch hier angesïßte Milch, die gern aufgenummen und gut vertragen wurde. Bereits nach 3 Stunden komnten in manchen Fällen Fettröpfchen in den oberflächlichen Partien der Mitteldarmzellen wahrgenommen werden. Während aber bei (j)tïitterung die Resorption nicht weiter ging, kam es hier zu einer vollständigen Verdaumg des in der Milch enthaltenen Fettes. Bei einem nach 24 Stunden getöteten Camponotusweibchen, das reichlich Milch gefressen hatte, war der Kropf leer, in den Zellen des Rektums war ebenfalls kein Fett nachzuweisen, dagegen erwiesen sich die Randzellen des Mitteldarmes mit verschieden großen Fetttrößf chen stark gefüllt. Die im Rektum befindlichen Kotmassen waren fast vollkommen fettfrei. Eine Resorption im Rektum lieh sich wie gesagt nicht feststellen.

Es darf nicht verschwiegen werden, lab häufig auch im Mitteldarm ron Tieren, die Nilch gefressen hatten, Resorption nicht beobachtet werden konnte. Ich schreibe dies aber nicht wechselnden Sekretionsstadien im Sinne śteunes's zu, sondern glaube annehmen zu dürfen, daß es sich in diesen Fällen entweder um zu alte oder zu junge Randzellen handelte. Die zu alten werden aber zu einer normalen Sekretions- ind somit auch Resorptionstiatiolieit nicht mehr, die zu jungen noch nicht imstande sein. Bei der lebhaften periodischen Epithelerneutung im Mitteldarm von Camponotus kamn dies Verhalten nicht weiter wundernehmen.

Sofort nach dem Fang konservierte Hymenopteren.

Man findet das Darmepithel der anf Bliiten oder an Obst gefangenen Hymenopteren verhältnismäbig recht selten in Fettresorption. Es mage dies dather kommen, dab sich die meisten Formen nach Füllung ihres Kroptes in ihren biall oder sonst einen versteckten Ort zuriickzuziehen pflegen und deshall gewöhnlivh nicht zur Verfügung stehen. bine Ausmahme matuen die sehr trägen 
Tenthrediniden aus den Gattungen Allantus und Macrophya, die gleich an Ort und Stelle die aufgenommene Nahrung ${ }^{1}$ ) verdauen. Infulgedessen enthielten die untersuchten Exemplare fast immer Fetttröpfchen in den Randzellen besonders des hinteren Mitteldamabschnittes; doch sind die Tröpfchen klein und nicht allzu zahlreich (Textfig. 8). Desgleichen waren die Zellen des Rektums häufig stark mit Fett gefiillt (Tafelfig. 10) und stelıt also die Rektalverdaumng der Honigbiene nicht vereinzelt da. Außerdem fand ich resorbiertes Fett, und zwar ausschließlich in den Randzellen des Mitteldarmes, nur noch bei verschiedenen Andrenen, bei Anthophora, Formica rufa, Pompilus viaticus (Tafelfig. 3) und einem Odynerus.

Daß es sich in allen diesen Fällen hauptsächlich um wirkliche Fettresorption, und nicht etwa bloß um Bildung von Fett aus eiweißartiger Substanz, wie sie Wernuand von der Calliphoralarve nachwies, oder um gespeichertes Fett, wie es für Periplaneta wahrscheinlich ist, handelt, lehrt das Verschwinden des IIilchfettes im Darmkanal von Camponotus, das des Pollenfettes in dem der Bienen und 'Tenthrediniden ohne weiteres. Im Gegenteil wird man auf' Grund der Befunde an Wespen und dem ausnahmslosen Fehlen von Fettanhäufungen in den Darmepithelien bei fettfreier Kost den Imagines der Hymenopteren iiberhaupt das Vermögen. in den Darmzellen Fett aufzubauen, absprechen müssen.

Zusammenfassung. Im allgemeinen läßt sich sagen: die Fïhigkeit der Fettresorption ist bei den Imagines der Hymenopteren gering. Vit Ausnahme der Formiciden, speziell Camponotus, war eine Resorption verfütterten Fettes nicht nachzureisen. Resorption des Pollenfettes wurde nur bei Formen mit wohlentwickeltem Mitteldarmepithel beobachtet. Daß die offenbar rückgebildeten Epithelien der Chrysididen und Ichneumoniden, deren Nahrungsanfuahme sich anf gelegentliches Naschen von Blütennektar und Pollen beschränkt, stets frei von resorbiertem Fett gefunden wurden, war ron vornherein zu erwarten. Bemerkenswerter ist schon, dab auch die Sphegiden das gleiche Verhalten zeigten, doch verbietet die beschränkte Anzahl der untersuchten Exemplare, ihnen die Fähigkeit der Fettresorption abzusprechen. Desgleichen mag es vielleicht zufïllig sein, daß sich die sofort nach dem Fang untersuchten Hummeln nicht in Fettresorption befanden; daß es bei den gefütterten eben-

1) Erwähnenswert erscheint mir noch, daß ich im Darmkanal von Allantus von 7 Fällen zweimal Insektenreste fand, weshalb man bei dieser Räuberei wohl nicht bloß von einer gelegentlichen Perversität, wie sie etwa auch bei der Honighiene beobachtet wurde, sprechen darf. 
falls zu einer Fettresorption nicht kam, wird wenigstens begreiflich. wenn man bedenkt, dab es sich wie bei den Bienen um Formen handelt, die streng an eine bestimmte Nahrung angepabt sind. Im hohen Grade auffällig erscheint mir das Verhalten der omnivoren Wespen. Es bleibt die Annahme übrig; das von den Sekreten gespaltene Fett würde erst außerhalb des Epithels wieder aufgebaut, da man aber das Milchfett angenscheinlich unvermindert im Rektum vorfindet, wird man kaum fehl gehen, wenn man den Wespen zumindest eine nur sehr geringe Fähigkeit, Fett zu resorbieren, zuspricht.

Hervorzuheben ist ferner, daß nur die jungen Brutbienen und die überwinterten Bienen imstande sind, den Pollen vollkommen auszuniitzen.

Nur bei Camponotus kan es zur Verdaumg des rerfütterten Fettes. Wir sahes, daß das Mitteldarmepithel der Formiciden gewisse larvale Charaktere erkennen läßt, und ich glaube, daß grerade hierdurch die stärkere Resorptionskraft erzielt wird. Bekanntlich ist bei den Larven der Bienen, Wespen und Ameisen der Mitteldarm hinter den Malpighi'schen Gefäßen geschlossen. Es wird dies dadurch möglich, daß diese Larven schon vorbereitetes, von unverdaulichen Beimengungen einigermaßen befreites Futter verabreicht bekommen. Selbstverständlich ist infolge der verhinderten Defäkation eine "Luxuskonsumption", wie sie etwa bei den Raupen der Lepidopteren stattfindet, vollkommen ausgeschlossen und ein starkes Resorptionsvermögen unbedingt anzunehmen. Dies bleibt aber den langlebigen, zn beträchtlicher Nahrungsaufnahme gezwungenen Imagines der Ameisen infolge der ähnlichen Struktur des Fpithels erhalten.

Ton besonderem Interesse ist die beobachtete Resorption im Rektum der Tenthrediniden und der Honigbiene. Lis ist dies ein ähnliches Verhalten, wie es Sпмиоти und Mrqiazzixi der sackförmigen Erweiterung des Enddarmes bei den Larven der Lamellikornier zuerkennen. Man muß sich wundern, daß ron der Honigbiene der Vorgang nicht schon längst beschrieben ist, es erklärt sich aber vielleicht daraus, daf wohl meist die bequemer zu beschaffenden Trachtbienen zur Untersuchung gekommen sein mögen. 


\section{Literatur.}

1. Aduterz, O., Om digestionssekretionen jemte nägra dermed sammenhängende fenomen hos insekter och myriapoder. Bib. Svensk. Vet. Akad. Handl., Vol. 12, 1890.

2. Berlese, A., Li Insetti. Mailand 1909.

3. Biedermann, W., Beiträge zur vergleichenden Physiologie der Verdauung. Pflüger's Arch. f. Phys., Bd. 72, 1898.

4. - Die Ernährung der Insekten. Winterstein's Handbuch d. vergl. Phys., Jena 1910.

5. Bizzozzero, J., Über die schlauchförmigen Drüsen des Magendarmkanals und die Beziehungen ihres Epitbels zu dem Oberflächenepithel der Schleimhaut. Arch. f. mikr. Anat., Bd. 44, 1893.

6. Bordas, L., Anatomie du tube digestif des Hyménoptères. C. R. Acad. Science, Paris, T. 118, 1894.

7. - Glandes des Hyménoptères. Annal. de Science nat. Paris, T. 19, 1895.

8. - Sur le revêtement épithélial cilié de l'intestin moyen et des coecums intestinaux chez les insectes. Bull. Soc. Ent. France, 1900.

9. - Le Jabot et le gésier de quelques Vespidae. Zeitschr. f. wiss. Insektenbiologie, Bd. 1, 1905 .

10. Bugnion, E., Recherches histologiques sur le tube digestif du Xylocopa violacea. C. R. 85, 1902.

11. Chun, C., Über den Bau, die Entwicklung und physiol. Bedeutung der Rektaldrüsen bei den Insekten. Frankfurt a. M. 1873.

12. Cúńnot, I., Etudes physiologiques sur les orthoptères. Arch. de Biol., Bd. 14, 1895 .

13. Deegener, P., Beiträge zur Kenntnis der Darmsekretion. Arch. f. Naturgesch., Bd. 75, I, 1909.

14. Dufour, L., Recherches anatomiques et physiol. sur les Orthoptères, les Hyménoptères et les Neuroptères. Mem. Sav. étrang. Akad. de Sc., T. 7, 1841.

15. FAusseK, V., Beiträge zur Histologie des Darmkanals der Inselkten. Zeitschr. f. w. Zool., Bd. 45, 1887.

16. Erenzeu, J., Einiges über den Mitteldarm der Insekten. Arch, f. mikr. Anat., Bd. 26, 1885.

17. - , Über Bau und Tätigkeit des Verdauungskanals der Larve von Tenebrio molitor. Zool. Anzeiger, Vol. 5, 1882.

18. FüRTH, O. v., Vergleichende chemische Physiologie der niederen Tiere. Jena 1903.

19. VAN GEHUChtEN, Recherches histologiques sur l'appareil digestif de la Ptychoptera contaminata. La Cellule, T. 6, 1891.

20. - Le mécanism de la Sécretion. Anat. Anzeiger, Bd. 6, 1891.

21. Houtz, H., Von der Sekretion und Absorption der Darmzellen bei Nematus. Anat. Hefte, Merkel-Bonnet, Bd. 39, 1909.

22. JoRDAN, H., Vergleichende Physiologie der wirbellosen Tiere, Bd. I. Jena 1913.

23. Küstenmacher, M., Zur Chemie der Honigbildung. Biochem. Zeitschr., Bd. 30, 1910.

24. LeUCKART, R., Anatomisch-physiologische Übersicht des Tierreiches. Vgl. Anat. u. Physiol., Stuttgart 1852. 
25. MingazziNi, P., Ricerche sul cauale digerente dei Iamellicorni fitofagi. Mitteil. Zool. Stat. Neapel, 1889-91.

26. Möвusz, A., Über den Darmkanal der Anthrenuslarve nebst Bemerkungen über Epithelgeneration. Arch.f. Naturgesch., 1894.

27. PaCkard, A. textbook of Entomologie. New York 1898.

28. Petersex, H.. Die Verdaung der Honigbiene. Arch. f. ges. Physiol., Bd. $145,1912$.

29. Petrunkewitsch, A., Die Verdaumgsorgane von Periplaneta orientalis und Blatta germanica. Zool. Jahrb., Anat. Abt., Bd. 19, 1900 .

30. Plateau, F., Recherches sur les phénomènes de la digestion chez les insectes. Mem. Ac. R. Belg., Vol. 41, 1875.

31. - Note additionelle au memoire sur les phénomènes de la digestion chez les insectes. Ibid. Vol. 43, 1877.

32. Rampohk, K., Abhandlung über die Verdaumngswerkzeuge der Insekten. Halle 1811.

33. Rerger, C., İber die Veränderung des Darmepithels bei Tenebrio molitor während der Metamorphose. Zeitschr. f. wiss. Zool., Bd. $62,1897$.

34. - Über die periodische Abstoßung und Neubildung des gesamten Mitteldarmepithels bei Hydrophilus, Hydrous und Hydrobius. Ibid. Bd. 63, 1898.

35. Rusgrts, H., Der Darmkanal von Dytiscus marginalis. Ibid. Bd. 98, 1911.

36. Schmemexz, P., Über das Herkommen des Futtersaftes und die Speicheldrüsen der Bienen. Ibid. Bd. 38, 1883.

37. Schlüter, K., Beiträge zur Physiologie und Morphologie des Verdauungsapparates der Insekten. Zeitschr. f. allg. Physiol., Bd. 13, 1911.

38. Schremer, A., Ïber den Darmkanal der Arthropoden. Zool. Beitr.. (Schneider's), Bd. 2, 1887.

39. Semichon, L., Recherches morphologiques et biologiques sur quelques Mellifères solitaires. Bull. Scient. France et Belg., T. XL, 1906.

40. Simroth, H., Über den Darmkanal von Osmoderma eremita. Giobel's Zeitschr. f. d. ges. Naturw., Bd. 51, 1878.

41. - Einige Bemerkungen über die Verdauung der Kerfe. Ibid. Bd. 51, 1878.

42. Sinety, R. DE, Pretendue absorption de graisse par le jabot chez les Blattes. Bull. Soc. Ent. France, 1901.

43. Steuder, A., Absorption und Sekretion im Darm von Insekten. Zool. Jahrb, Bd. 33, 1913.

44. 'Tanet, C., Anatomie du gaster de la Myrmica rufa. Paris 1902.

45. Vignon, Critique de la théorie vésiculaire de la sécrétion. Arch. Zool. exp., Vol. 7, 1899.

46. Vorxow, N., Epithalium digestif des nymphes d'Aeschna. Bull. Soc. Sc. Bucarest, Vol. 7, 1898.

47. Wernlaxd, E., Öber Bildung von Fett aus eiweiBartiger Substanz im Brei der Calliphoralarven. Zeitschr. f. Biol., Bd. 51, 1908. 


\section{Erklärung der Abbildungen zu Tafel I und den 'Textfiguren.}
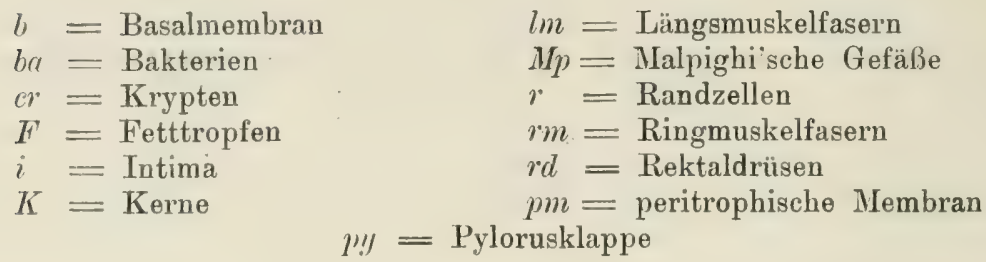

Fig. 1. Apis mellifica. Längsschnitt. Das Mitteldarmepithel in Fettresorption.

Fig. 2. Idem. Längsschnitt durch den hinteren Teil des Mitteldarmes. Pylorusklappe. Epithel in Fettresorption.

Fig. 3. Pompilus viaticus. Idem.

Fig. 4. Camponotus ligniperdus. Längsschnitt. Mitteldarmepithe im Beginn der Resorption.

Fig. 5. Idem. Tangentialschnitt in Höhe der Randzellenkerne.

Fig. 6. Camponotus ligniperdus. Ausgewachsene Larve. Peritrophische Membran. Doppelter Stäbchensaum. Die Randzellen stehen vor dem Abgestoßenwerden. Die Kerne sind deformiert.

Fig. 7. Camponotus ligniperdus. Imago. Mitteldarmzellen in Fettresorption.

Fig. 8. Apis mellifica. Querschnitt durch das Rektum in Höhe der Rektaldrüsen. Epithel in Fettresorption.

Fig. 9. Apis mellifica. Enddarmzellen in Resorption.

Fig. 10. Allantus spec. Idem. 

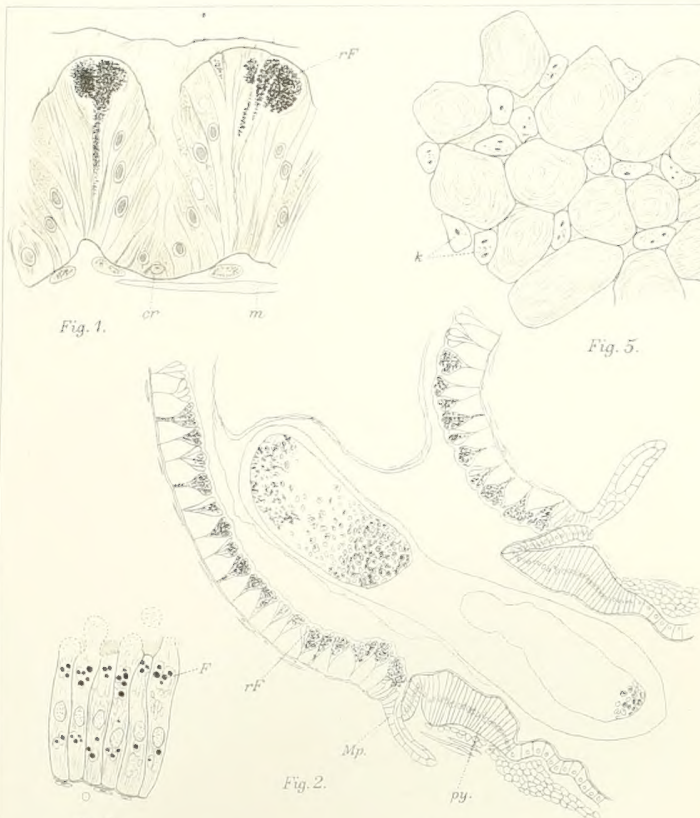

Fig. 3 .

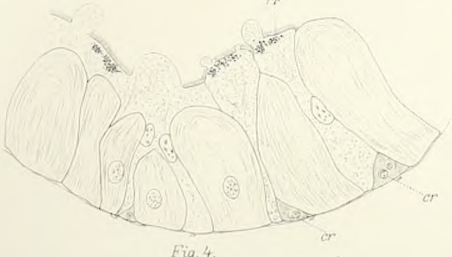

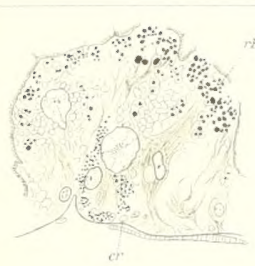

Fig. 7.
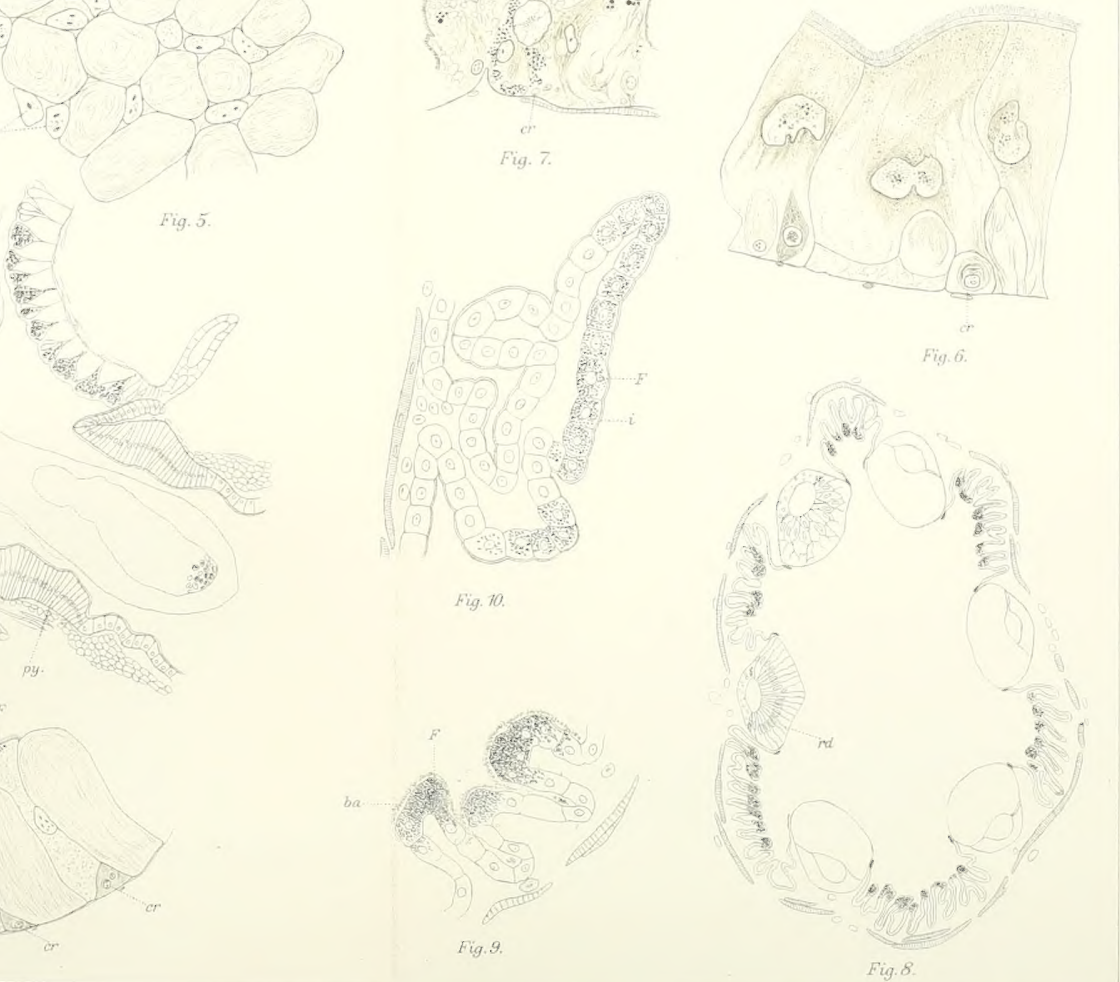



\section{Lebenslauf.}

Der Verfasser vorliegender Arbeit, Kunt Loele, ev. Konfession, wurde am 28. September 1888 zu Döschnitz bei Schwarzburg als Sohn des Pfarrers Hermann Loele und seiner Gemahlin Luise, geb. Bergmann, geboren. Er besuchte 9 Jahre lang das Gymnasium zu Rudolstadt und studierte dann zuerst 3 Semester in Leipzig, dann 2 in Jena, hierauf wieder in Leipzig Naturwissenschaften.

Meine akademischen Lehrer in Leipzig waren die Herren BraHs, Chun, Credner, Dittrich, Fischer, Hantzsch, Held, Jungmann, Miehe, Pfeffer, Rinne, zur Strassen, Steche, Volkelt, Wagner, Wiener, Woltereck, Wundt und Zirkel. 


\section{4|||| $\mid$}

G. Pätz'sche Buchdr. Lippert \& Co. G. m. b. H., Naumburg a.d.S. 